Año XLVIII. urtea

$122-2016$

Uztaila - abendua

Julio - diciembre

5

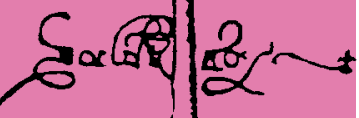

sus

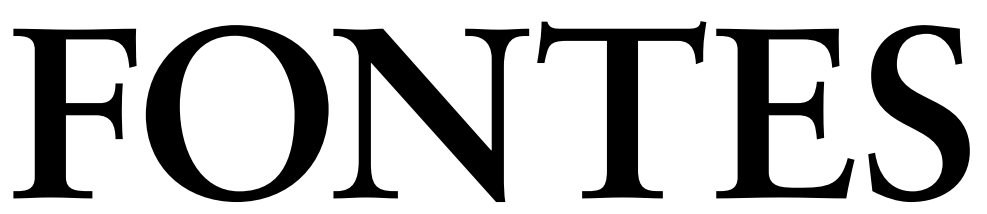

LINGVÆ

VASCONVM

STVDIA ET DOCVMENTA

SEPARATA

Zozo zuriaren xerka: euskararen optatiboaren historia

Manuel Padilla-Moyano

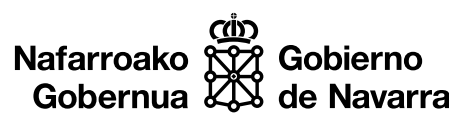

0000 


\section{Sumario / Aurkibidea}

\section{Fontes Linguae Vasconum. Studia et Documenta}

Año XLVIII. urtea - N. o 122. zk. - 2016

Uztaila - abendua / Julio - diciembre

Erroibarko aldaeraren inguruan

(3 - Hego Erroibarko azpialdaera. Bigarren erdia)

Koldo Artola

Etxarrierako hitano-alokutiboa

Jose Luis Erdozia

An introduction to Basque aspiration: the contribution of onomastics

Patxi Salaberri Zaratiegi, Iker Salaberri Izko

Urretabizkaiaren eta Sarrionandiaren itzulpen-habitusak

Miren Ibarluzea

Julian Gaiarreren euskal gutuna: edizioa eta azterketa

Koldo Ulibarri

Zozo zuriaren xerka: euskararen optatiboaren historia

Manuel Padilla-Moyano

Euskarazko erlatiboen diakroniaz: testu zaharren azterketa

Dorota Krajewska 


\title{
Zozo zuriaren xerka: euskararen optatiboaren historia
}

\author{
Manuel Padilla-Moyano ${ }^{1}$ \\ UPV/EHU \& U. Bordeaux Montaigne
}

\section{SARRERA}

Munduko hizkuntzen artean gutxik dute, flexio mailan, modu berezi bat igurikimen eta desioen adierazpenarentzat. Modu hori optatiboa da, eta euskara zaharraren aditz sistemak halakorik zuen. Aditz joko hori ai $(t)$ - aurrizkiaren bidez eratzen zen, perpausean ordena markatua agerraraziz. Haren bakantasun tipologikoagatik, eta zenbait puntu argitu beharra dugulako, lan honek euskararen optatiboaren deskripzio diakroniko bat eskaini nahi du. Oinarrizko kontzeptualizazioa eginik (§ 1), ai (t)-aurrizkidun formez arituko gara, gramatikagintzari ( $\$ 2.1)$ zein testuei ( $\$ 2.2 \& 2.3$ ) begiratuz. Haren eremuaz eta iraupenaz gogoetaturik $(\$ 2.4)$, ai $(t)$ - aurrizkiaren jatorriaz jardunen dugu, hipotesi berri baten formulatzeko ( $\$ 2.5)$. Ondoko atalean, euskarak igurikimen eta desioen adierazteko dituen gainerako bideak aztertuko dira: $b a$ - aurrizkia (§ 3.1) eta harekiko konbinazio diren ai ba- (\$3.2) zein aments ba- (\$3.3) egiturak, alba- aurrizki konplexua (\$3.4), balinba (§ 3.5), oxala (\$ 3.6) eta abal (\$ 3.7) partikulak, gehi Jainkoari lotutako formulak (\$3.8).

1 Lan hau ondoko ikerkuntza talde eta egitasmoetan kokatzen da: «Monumenta Linguae Vasconum V: periodizazioa eta kronologia» (Ekonomia eta Lehiakortasun Ministerioa, FFI2016-76032-P); «Euskal Hizkuntzaren Historia eta Hizkuntzalaritza Historiko Konparatua» (Eusko Jaurlaritza, GIC. IT698-13) eta «Hizkuntzalaritza teorikoa eta diakronikoa: gramatika unibertsala, hizkuntza indoeuroparrak eta euskara» (UPV/EHU, UFI11/14). Bihoa nire esker hoberena Beñat Oyharçabal, Blanca Urgell eta aldizkari honen bi errebisatzaile anonimorendako, lan honi egin dizkioten ohar ezin pagatuzkoengatik. Erran gabe doa, nihaur naiz huts ororen erantzule bakarra. 


\section{ATARIKOAK}

\subsection{Optatiboa: hurbiltze bat}

Musik lau desio mota definitu ditu, desiratzen diren egoerekiko bateragarritasunaren arabera:

I have called want the notion of desire which is incompatible with a desired state of affairs in the past, hope a desire referred to an SoA no matter the timing and without any commitment of the subject about the realization of the desired SoA, wish 1 the type of desire in which the Wanter predicts that the desired SoA is unlikely to realize, and wish 2 the notion in which the subject of desire is sure that the desired SoA has not occurred. These notions, which are not encoded by different linguistic items in every language of the sample, are meant to work as descriptive tools to account for the complexity underlying the semantics of desire (2016: 25).

Lan honetan igurikimen («hope») eta desioez arituko gara, pertinente izanen delarik azkenen arteko bereizkuntza eginez, agiantza («wish 1») eta dolu («wish 2») terminoen bidez zehazturik.

Munduko hizkuntzetan igurikimen eta desioaren adierazpena hainbat eratara gauzatzen ahal da. Hizkuntza batzuek estrategia sintaktikoak garatzen dituzte; beste batzuek, morfologikoak. Adierazten den desioa iraganaldiari buruzko proiekzioa den ala ez den -hots, gertatu ez denarekiko dolu edo erregreta ala egiazko agiantza, hurrenez hurren-, eta horren arabera, baliabide morfosintaktiko desberdinak aurkitzen ahal ditugu. Erdara handien eta ezagunenetarik baizik ez aipatzeko, eta betiere beste aukeren artean, kontrafaktualtasunaren eremuan ingelesez maiz 'desiratu' aditza baliatzen da (1), errusieraz zein frantsesez baldintza eliptikoa (2-3), eta gaztelaniaz ojalá partikula (4).

(1) I wish I had come!

ni desiratu ni AUX.PST etorri.PFV

'[Nahi nuke] etorri izan banintz!'

(2) Если бы я прищел!

baldin SUBJ ni etorri.PFV

'Etorri izan banintz!'

(3) Si j'étais venu!

baldin ni AUX.SUBJ etorri.PFV

'Etorri izan banintz!'

(4) ¡Ojalá hubiese venido!

oxala AUX.SUBJ etorri.PFV

'[Oxala] etorri izan banintz!'

434 Fontes Linguae Vasconum (FLV), 122, julio-diciembre, 2016, 433-462

ISSN: 0046-435X ISSN-e: 2530-5832 
Gertatu ez denarekiko dolutik kanpo, erran nahi baita gertagarri diren desioen eremuan -logikaren aldetik bederen-, ingelesez gehienbat aditz modalak erabiltzen dira (5), errusieraz geroaldian oinarritutako sintaxi markatua, besteren artean (6); frantsesez aukerarik ezagunenak plaise/ plùt à Dieu formula eta subjuntiboa konbinatzen ditu (7), eta gaztelaniaz ojalá partikula gehi subjuntiboa (8).

(5) May she live forever!

AUX (modal) hura.F bizi betiko

'Betiko biziko ahal da!'

(6) Будет ли она жить вечно!

AUX.FUT PTCL hura.F bizi betiko

'Betiko biziko ahal da!'

(7) Plût à Dieu qu' elle vécût pour toujours!

laket.SUBJ DAT jainkoa COMPL hura.F bizi.SUBJ -ko beti

'Jainkoari laket bekio hura betiko bizi ledin!'

(8) ¡jalá viva/ viviese para siempre!

oxala bizi.suBj -ko beti

'Betiko biziko ahal da!'

Aldiz, hizkuntza batzuetan desioen adierazpenak flexio mailako gauzatzea du, aditz sisteman modu berezi bat agerraraziz, optatibo deitua ( $c f r$. lat. optãre 'hautatu' edo 'desiratu'): «The mood category expressing realizable wishes or hopes [...]. Some languages exhibit a distinct grammatical form for this purpose» (Trask, 1993: 195). Bybeek, Perkinsek eta Pagliucak igorleari orientatutako modalitatean sailkatzen dute optatiboa, «The wish or hope of the speaker expressed in a main clause» (1994: 179). Desiraren adierazpeneko estrategien artean, flexiozkoak versus ez-flexiozkoak bereizi beharretan gara, hain zuzen, optatibo terminoak igorlearen desio baten adierazteko baliatzen den aditzaren jokoa izendatzen baitu. Tipologia lanetan optatiboaren etiketa comparative concept gisara onartua da (cfr. Haspelmath, 2010), gramatika deskripzioan bestelakorik ere aurki daitekeelarik (Dobrushina, Van der Auwera \& Goussev, 2013):

a) Zenbaitetan optatibo terminoa erabili izan da, nahiz eta delako hizkuntzan desioen adierazpena kategoria horren funtzioetarik bat baizik ez izan, eta ez zentrala; hala gertatzen da Na-Dené familiakoa den slave delako hizkuntzan (Rice, 1989).

b) Turkologiaren tradizioan, optatibo terminoa 1. pertsonaren aginteraren izendatzeko baliatu izan da -nazioarteko literaturan usuenik hortative edo exhortative deitzen dena-.

c) Ameriketako hizkuntzetako optatiboa zenbaitetan desideratibo etiketa pean bildua izan da; halaber, sino-tibetar familiako ladakhiera hizkuntzarentzat benedictive erabili izan da. 
Hizkuntza batek optatiboa duen ala ez ebazteko, Dobrushinak, Van der Auwerak eta Goussevek (2013) hiru murriztapen ezartzen dute: i) flexiozkoa izan behar du, erran nahi baita aditz jokadura mailakoa; ii) pertsona guztiekin posible izan behar du; eta iii) desioen adierazpena behar du funtzio nagusi. Horrela ulerturik, munduko hizkuntzen artean optatiboa dutenak gutxiengoan dira, nonbait zazpiren batean ${ }^{2}$.

Historikoki euskarak ere modu optatiboa ukan du, aipatu hiru murriztapenak betetzen dituena. Bereziki hirugarrenaren kasuan, euskararen optatibozko formek soilik igurikimen eta desioak adierazten dituzte. Ikusiko denez (\$2.1), forma horiek ai(t)- aurrizkiaren medioz eratzen dira, perpausaren hastapenean, tipikoki [AD. LAGUNTZAILE - AD. NAGUSI] hitz ordena markatua agerraraziz (9-10) -zentzu horretan, euskararen optatiboa aldi berean flexiozkoa eta sintaktikoa litzateke-.

(9) Ainintz etorri! '[Oxala] etorri (izan) banintz!'

(10) Ailedi bizi betiko! 'Betiko biziko ahal da!'

\subsection{Optatiboari lotutako kategoriak}

Ondoko lerroetan gaindi optatiboari estuki lotuak zaizkion nozio batzuk aipatuko ditugu, Dobrushina, Van der Auwera eta Goussev-en 2013ko lanetik abiaturik.

Desioen adierazpena maiz subjuntiboari lotua agertzen da. Definitzeko zail izan badaiteke ere, oro har subjuntiboa irrealis balioei lotzen zaie, maila sintaktikoan mendeko perpausei, edo bederen mendeko perpausen mota batzuei. Nolanahi ere den, subjuntiboa -morfologikoa nahiz sintaktikoa izan- desioen adierazpenari lot dakioke, (1-8) adibide sortan ikusi denez. Puntu honetan pausa daitekeen galdera hau da: nola bereiz optatibo morfologikoa eta subjuntibo morfologikoa? Bada, optatiboaren definitzean formulatu diren murriztapenak gogoan (vid. supra), hirugarrenak desioen adierazpenak funtzio nagusia izan behar duela ezartzen du; hala ere, zenbaitetan bien arteko muga lausoegia gerta daiteke.

Bestalde, modalitatearen barnean desiderative kontzeptua dugu (Bybee \& Fleischman, 1995). Optatiboak zein desideratiboak desioaren adierazpena inplikatzen dute, baina lehenak igorlearen desioa adierazten du eta bigarrenak beste zein-nahi partaiderena adieraz dezake. Euskalaritzaren tradizioan maiz botibo edo opazko (desideratibo) bezalako terminoak erabili izan dira optatibozko formen deskribatzean ( $c f r$. 3. oinoharra).

2 Zehazki, World Atlas of Language Structures delakoaren arabera, aztertutako 319 hizkuntzetarik 48k dute flexiozko optatiborik (Dobrushina, Van der Auwera \& Goussev, 2013); bidenabar, lan horretan euskara «optative absent» etiketaz agertzen da (Saltarelli et al., 1988). Optatiboa dutenen arteko gehienak Kaukason eta Ipar Indian kokatuak dira; Asian eta Ameriketan kasu bakan batzuk dira; Australian eta Afrikan ez da ageri, eta Europan, biga baizik ez: albaniera eta karaymera (Lituania eta Krimeako hizkuntza turkikoa, ehun hiztunen ingurua duena). Iraganeko hizkuntza egoerak kontuan hartuz, familia indoeuroparraren barnean honakoak ere aipa ditzakegu: sanskritoa, antzinako grekoa, armeniera, gotikoa eta prusiera zaharra. 
Azkenik, aginterak ere desioen adierazpenari lotuak ager daitezke. Bai aginterak, bai optatiboak hiztunaren desioa adierazten dute, baina diferentzia batez: aginteraren kasuan, desio horren betetzea hiztunaren ahalmen edo eraginpean sartzen da, eta hiztunak entzuleari dei egiten dio desio hori konpli dezan; optatiboan, aldiz, adierazten den desioa hiztunaren ahalmen edo eraginpetik kanpo gertatzen da.

Perspektiba diakronikotik, hau guztia optatiboaren gramatikalizazioari estuki lotua da: «There are several natural sources for a true optative sentence type: future tenses, conditional or subjunctive moods, and imperative moods. Any of these might become specialized as an optative during the history of a language. Yet in few of the languages known to us has this specialization occurred» (Sadock \& Zwicky, 1985: 164).

\section{MODU OPTATIBOA EUSKARAZ 3}

\subsection{Ai(t)- aurrizkidun formak gramatiketan}

Euskal optatiboarekiko lehenbiziko aipamena Oihenartena da. Harentzat optatiboa aditz sistemaren bost moduetarik zen, indikatibo, agintera, baldintzazko eta subjuntiboarekin batean, jokamolde trinkoan (1656: 65v) nahiz perifrastikoan (ibid.: 66v or.) ${ }^{4}$. Zehazkiago, optatibozko forma perifrastikoen artean, batetik *edin \& *ezan laguntzaileekikoak jaso zituen, eta bestetik izan \& *edun parearekikoak. Azken hauetan bi forma bereizten zituen: inperfektibozkoa (ainins egoiten) eta perfektibozkoa (egon ainins) (ibid.: 68 . or. $)^{5}$.

XIX. mendean zubereraren gramatikagile nagusiek ere optatiboa jaso zuten. Chahok «conditionnel abstrait» etiketa pean bildu zuen (1836: 158), eta horri jarraiki zitzaion

3 Lan honetan optatibo terminoa hobesten dugu, zehaztasunagatik eta nazioarteko literaturarekiko koherentziagatik: modu gramatikal batera igortzen du (OPT), eta halakoa da euskarak historikoki izan duena; bidenabar, euskararen aditz sistemaren lehenbiziko deskripzioan horrelaxe izendatu zen: optativus (Oihenart, 1656). Atalean gaindi xehekiago ikusiko denez, Chahok conditionnel abstrait izendapena baliatzen du; Inchauspek, Gèzek, Van Eysek, Ithurryk eta Lafonek votif; Gavelek eta Lacombek, Lhandek, Larrasquetek eta Mounolek optatif. Lafittek aipamen berezia merezi du, zeren ai-dun formez aritzean votif erabiltzen baitu, baina balioari erreferentzia egitean optatif -hain zuzen, guk alderantziz eginen dugu-. Halaber, Lafittek euskarazko termino bat proposatu du: opazko (1980: 495), Casenave-Harigilek onetsia eta Etxegorrik baliatua. Dena den, ezaugarri honetaz jardun dutenek maizen botibo erabili dute (Zuazo, Oyharçabal, Etxebarne edo Camino). Finitzeko, Hualdek eta Ortiz de Urbinak ai(t)- aurrizkidun formak deskribatu ez badituzte ere, agiantzaren bestelako adierazpidez aritzean optative eta desiderative sinonimotzat hartu dituzte (2003: 297); orobat egin du Euskaltzaindiak, optatibo (1987: 418) zein desira (2002: 445) baliatuz.

4 «Optativus unicum habet tempus, præteritum imperfectum, ut ainansa utinam iacerem, aihansa iaceres, ailaza iaceret, aikeneunza iaceremus, aizeneunzae iaceretis, aileunza iacerent» (Oihenart, 1656: 65v) [...] «Optativo ainins utinam essem, aihins utinam esses, ailis utinam esset, aiquina utinam essemus, aizinete utinam essetis, ailira utinam essent» (ibid.: 66v or.).

5 «Optativum duo producit tempora, scilicet iunctum participio præsentis, præteritum Imperfectum Optativi, ut ainins egoiten utinam manerem; iunctum verò participio præteriti producit præteritum perfectum, ut egon ainins utinam mansissem» (Oihenart, 1656: 68). 
Belsunce (Mounole, 2003: 341-342 or.). Inchauspek votif bezala sailkatu zuen, bi aldi bereiziz: 1) geroaldia («ailédi! - ailéza! plut à Dieu qu'il...») eta 2) orainaldia («ailitz! plût à Dieu qu'il fut ! - ailu plût à Dieu qu'il eut !»). Gèzek ere bi aldi horiek eman zituen, "edin \& *zan laguntzaileekin eratuei potentzialaren ñabardura esleituz: "aikina plût à Dieu que nous fussions - aikinte puissions-nous être» (1873: 95); orobat egin zuen Van Eysek (1879: 232). Bonapartek paradigmarik osoena eskaini zuen (ikus 1. taula). Ithurryrentzat, azkenik, "Le votif est formé du suppositif [= baldintzazkoa] en remplaçant $b a$ initial par ai. Ex. : Ailego, plaise à Dieu qu'il restât (actuellement)» (1895: 63). Ithurryk orainaldikoa zein burutua bereizi zituen: "Ailu eramaten, plaise à Dieu qu'il l'emporte ; Ailu eraman, plût à Dieu qu'il l'eût emporté»(ibid.: 76. or.), “edin laguntzailearekiko formak ere jasoz (ibid.: 94. or.); beste pasarte batean optatibozko perpausen sintaxi markatuaz ohartarazi zuen: «Dans les phrases affirmatives à tous les temps (à part le votif), les infinitifs se placent, en général, devant les verbes auxiliaires» (ibid.: 383. or.).

1. taula. Optatiboa Bonaparteren lanean (1869 I: 7. taulatik egokitua).

\begin{tabular}{|l|l|l|}
\hline Optatif du conditionnel & $\begin{array}{l}\text { présent } \\
\text { parfait } \\
\text { parfait absolu } \\
\text { parfait antérieur } \\
\text { parfait antérieur absolu }\end{array}$ & $\begin{array}{l}\text { ailitz erorten! 'tombât-il !' } \\
\text { ailitz eroririk! 'fût-il déjà tombé !' } \\
\text { ailitz erori izan! 'fût-il tombé !' } \\
\text { ailitz izan eroririk! 'fût-il déjà tombé !' }\end{array}$ \\
\hline Optatif du potentiel conditionnel & $\begin{array}{l}\text { futur } \\
\text { futur antérieur }\end{array}$ & $\begin{array}{l}\text { ailedi eror! 'tombât-il !' } \\
\text { ailedi izan eroririk! 'fût-il déjà tombé !' }\end{array}$ \\
\hline
\end{tabular}

xx. mendean ere optatiboa bildua izan da. Bonaparteren ildotik, Gavelek eta Lacombek zortzi aldi proposatzen dituzte optatiboarentzat: «présent simple : ailu | présent en action : ailu ikusten | parfait : ailu ikusi | parfait composé : ailu ikusi ukan | présent propositif : ailu ikusiren I parfait propositif : ailu ikusi ukanen I futur présent : aileza ikus I futur parfait : aileza ikusi ukan» (1937: 60). Larrasquetentzat bi aldien arteko desberdintasuna denborazkoa litzateke: orainaldian eta geroaldian «ainendi abia plaise à Dieu que je parte», eta iraganaldian «ainintz abiatu plût à Dieu que je fusse parti(e)» (1939: 36-37). Casenave-Harigilek oraineko eta geroaldiko formak eman ditu, soilik joskera perifrastikoan (1993: 492, 507, 522 \& 535). Azkenik, Caminoren arabera optatiboa "balizko adizkerekin, "edin eta "ezan aditz laguntzaileekin eta aditz trinkoekin baliatzen zen, eta denboraren aldetik, oraina, iragana nahiz etorkizuna adieraz zitzakeen» (2013: 121).

Laburbilduz, euskararen optatiboa aditz jokadura mailan gauzatzen da, pertsona guztietan joka daiteke, eta soilik igurikimen eta desioen adierazpenerako baliatzen da; horrela, Dobrushinak, Van der Auwerak eta Goussevek (2013) kategoria horrentzat ezarri hiru murriztapenak betetzen ditu. $A i(t)$ - aurrizkia harturik, optatibozko formek sintaxi markatua agerrarazten dute: perpausaren hastapenean, eta aditz laguntzailea forma jokatugabearen ezkerrera. Joskera perifrastikoan, gramatikagileek gutxienez bi aldi bereizi dituzte optatiboaren baitan, lehena izan \& "edun laguntzaileekiko, eta bigarrena "edin \& *ezan parearekiko. Beraz, aditz nagusia gutxienez bi formatan ager daiteke: partizipioa -perfektiboa nahiz inperfektiboa- eta aditzoina. 


\section{2. $A i(t)$-dun optatiboa testuetan ${ }^{6}$}

Beharbada optatiboa deskribatu duten gramatikagileak Zuberoako euskaraz ari zirelako, edo haren formek lurralde horretan iraun dutelako luzeenik, bertako euskararen ezaugarritzat hartua izan da. Halere, Zuazok erremarkatu bezala (1989: 636), jada Van Eys ohartu zen Leizarragak eta Axularrek optatibozko formak baliatu zituztela (1879: 501), eta Lafonek ere beste zenbait adibide bildu zuen (1944 I: 494-495). Beraz, ai(t)-dun adizkiak ongi lekukotuak dira Lapurdiko testu zaharrenetan (11-16):

(11) Ailitez trenca çuec trublatzen çaituztenac. 'À la mienne volonté que ceux qui troublent vostre repos fussent retranchez'. (Lç Gal 5, 12)

(12) Ainençaçue supporta appurbat neure erhogoán. 'À a mienne volonté que vous me supportissiez vn petit en ma folie'. (Lç Cor II 11, 1)

(13) Aitzineçate regna, guc-ere çuequin batean regna deçagunçát. 'À la mienne volonté que vous regnissiez, afin que nous aussi regnions auec vous'. (Lç Cor I 4, 8)

(14) Baceaquizquiat hire obrác, ecen ezaicela ez hotz ez eraquin: aihinz hotz edo eraquin. 'Je sais tes œuvres, que tu n'es ni froid ni brouillant : à la mienne volonté que tu fusses froid ou brouillant'. (Lç Apok 3, 15)

(15) Hauc dira (eta Iaincoac ailliotsa liren asco) haraguiaren beccatuan ez erortceco [...] behar diren erremedioric principalenac. (Ax 419)

(16) Eta gaixtoeneko contuan, aillequitça hec ere, edo hec bedere gueldi. (Ax 173) ${ }^{7}$

6 Lan honetan bi corpus baliatu zaizkigu: hizkuntza osoari begira, Euskal Klasikoen Corpusa (EKC); Zuberoako euskararentzat, guhaurren tesiarena, XVI - XIX. mende bitarteko 40 testutik goiti biltzen duena. Hona testuen zerrenda, OEHren aipamen sistemaren araberako laburdurez emana -OEHtik kanpoko erreferentziak jarraian zehaztuko dira-: Lç (hiztegiñoa), O (Pro \& Po), Bela, Saug, Tt (Onsa \& Arima), PrS, Bp, CatOlo, Othoitce, Mst, IP, Ressegue, StJul, Mercy, NLilia, Egiat (I), Edipa, Xarlem, UskLi, CatS, Medit, CanBel, Etch, AztiB, Arch (Fab, Jenesa, Psalmiak, Ruth, Salomon), MaiMarHil, Myst, Ip (KurBD, Dial, BulaS, Imit, Apok), Anna Urruty (EvS, Epit), SGrat, AstLas (Urkizu, 1998). OEHren corpusetik kanpoko testu hauek erabili ditugu: Etchart (Zuberoa eta Erronkariko ibarren arteko gutun ofizialen barnean, Maulen sinatuak direnak, ca. 1616) (Bilbao et al., prestatzen), SteEli (Sainte Elisabeth de Portugal trajeria, ca. 1750; Baionako Euskal Museoko liburutegia, Ms. 14), DKhi (Doctrina khiristia haurren instruccionetaco, Cluzeau, Baiona, 1812; Vinson 171.c), Khurutch (Khurutchiaren bidiaren eguiteco praticac eta othoitciac (Vivent, Oloroe, 1838; Vinson 218), HOrdre (Heren-Ordreco escu libria igante-bestetaco officio berrieki, Lapeyrette, Oloroe, 1860; Vinson 314), eta Catuchuma españoul eskuizkribua (Hauze, 1899; Baionako Diozesaren Liburutegian aurkitua, katalogatu gabe).

7 Hona Axularren bi optatibozko formei egin zaizkien iruzkinak. AILEKITZA: «Aditzaren aurrizki hunek (ai-) gogo bat edo nahi bat aditzera ematen du. Ikus R. Lafon (1944 I: 394). Beherago dator beste kasu bat: ailio$t s a, 271$. Oihenartek hunela itzultzen du: 'pleust a Dieu qu'il dit' (RIEV, 4: 225)» (Villasanteren oharra, apud Urgell, 2015: 96); «beraz, 'oxala geldi balekizkio...!'» (Urgell, idem). AiLiotsA «ailezaio (opa)! ai balezaio!» (Urgell, 2015: 236, Lekuonaren oharra jasorik). Azkenik, aipa dezagun Larramendik bere Suplementon Jainkoak $\rightarrow$ Jainkoari zuzendu zuela, seguruenik aditzaren io datibotzat harturik (Urgell, 2000: eranskinak 303). Forma honetaz, cfr. 11. oharra. 
Adierazgarriago dena, mendebaldeko testu arkaikoetan ere ageri da optatibozko formarik (17-18); bigarrena ez da segurua, baina guri hala iruditzen zaigu ${ }^{8}$.

(17) Eder baliz, on ez eiliz. 'Fuese hermosa y no buena' (Garibay, A56), «referido a los que buscan en los matrimonios hermosura más que virtudes» \& Ederra bai

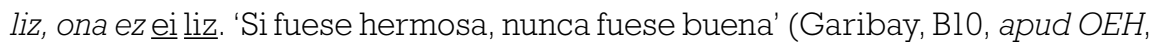
S.V. $a i(t)-)$

(18) Ay joat gauiraya / [...] Ayt joat gabiraia. (Perutxoren kanta, 4 \& 7, TAV, 104)

Beraz, euskara arkaikoan ai(t)- moldeko optatiboa gutxienez Aturri aldean zein Mondragoen lekukotua da. Ondoren, Lapurdin Axularrek (15-16) eta Etxeberri Ziburukoak (19) ai $(t)$ - aurrizkidun optatiboa baliatu zuten ${ }^{9}$, baina batez ere Pouvreauk, forma gehien eman duen idazleak ${ }^{10}$ (20-36). Haien artean izan \& "edun (20-27) zein "edin $\&$ *ezan laguntzaileekikoak (28-29), edo Jainkoari lotua den ailiotsa forma trinkoa ${ }^{11}$ (30-33) aurki daitezke; halere, markagarriena orainaldi morfologikoaren gaineko formarik eratu izana da, -(e)la edo -(e)n atzizkiez horniturik (34-36).

(19) Aitnetça hec [zure manu sainduak] / vngui guarda / Iauna ona, bethiere. (EZ Eliç 207-208)

8 «Ay joat gauiraya, v. 4. Ayt joat gauiraya, v. 7. Todos parecen inclinarse por la primera lección, que daría una interjección y una forma bipersonal de imperativo, que no parece estar directamente atestiguada en otra parte, "Ay, véteme, gavilán". De mantener ayt, se podría pensar en el prefijo ait(t)- (vizc. ant. ei) de "votivo" [...]. Pero esto exigiría una forma verbal distinta (de "pasado") y en todo caso el sentido vendría a ser aproximadamente el mismo" (Michelena, 1964: 104). Gure ustez, badira bigarren irakurketaren aldeko argudioak. Batetik, ayt ez optatibozko aurrizki, baizik eta auhenezko ai interjekzio gisara irakurtzeak inprentako huts baten zuzenketa inplikatzen du, zeinetan okerreko karakterea kasualki $t$ bailitzateke. Bestetik, Mitxelenak ayt joat formak optatiboa izateko iraganaldiko adizkia behar zukeela zioen arren, orainaldikoa ere izan liteke -cf. Acto 262, (37) adibidean edo, beste maila batean, Pouvreaurenak, (34-36) adibideetan-; nolanahi ere, ez litzateke harritzekoa bere azkenetan den ezaugarri baten aitzinean hiztunek halako zalantzarik ager lezaten. Azkenik, lehen irakurketak ere lekukotu gabeko forma bat eskatuko luke.

9 Lafonen arabera, Harizmendik ere ai(t)- moldeko optatiboa ezagutzen zuen (1944 I: 73); halere, guk ez dugu halakorik atzeman.

10 Pouvreauk optatiboaren hemeretzi agerraldi ematen ditu, ordura arteko gainerako egile guztiengan lekukotu ditugunak baino gehiago. Ezin ahantz daiteke Pouvreau euskaldun berria zela eta, beraz, idatzizko molde ikasiak erabiltzen zituela. Haren hiztegiaren iturri nagusien artean Oihenarten idazkiak dira; hori ez ezik, badakigu Pouvreauk Oihenartengana jo zuela laguntza eske: «aintzakotzat hartu behar da xvII. mendean euskaldun peto asko ez bide zirela gai izango Leizarraga baten hizkuntza arkaizantea, Etxeberri baten bertsogintza bihurria eta Axular baten prosa joria ulertzeko» (Etxagibel, 2014: 555). Hortaz, Pouvreauk «Oihenart izan baitzuen gidari nagusi eta ia bakarra» (ibid.: 580 or.), optatiboaren maiztasuna gehienbat mauletarraren eragipenari zor zaiola postula genezake; $c f r$. 11. oharra.

11 Ailiotsa adizkia Axularri hartua izanik ere, Pouvreauk Oihenarti galdegin zion forma horren erran-nahiaz: «Ailliotza, veut dire pleust a dieu quil dit» (Urquijo, 1910: 225). Gure ustez, Oihenarten erantzuna forma bere testuingurutik kanpo hartzetik datorke, *io 'erran' gisara harturik. Nolanahi ere den, ailiotsa adizkiaren gibelean datzan erroa ez dugu segur identifikatu; iduri luke *io izatea: beste kasu batzuetan gertatu den bezala, ailiotsa datibodun adizkia izan zatekeen, gero ergatibodun bilakatua; bidenabar, horren paraleloa izan liteke Jinkoak ailema/ ailemo (\$3.8). 
(20) Aininz baso zuri egun bateko bedere serbitzurik zuri egiteko dagotzun bezala. (SP Imit III 10, 4)

(21) Aigine mundu hunetan egun batez bedere prestuki ibilli. (SP Imit I 23, 2)

(22) Aitzine halakoa, aitzine etorri zeronek zure buruaren ez maitatzeko, bainan ere keinura xoilki behatzeko. (SP Imit III 32, 2)

(23) Zein laster iragaiten den munduko loria! Ailitzaio hekin bizitzea ardietsi zuten iakintasunari. (SP Imit I 3, 6)

(24) Ailitzaiku egun hura ilki! Ailute hemengo kauza guziek fin hartu. (SP Imit III $48,1)$

(25) Ailu Iainkoak nahi munduan diren guziak salba ahal banetza. (SP Dotrina «Quinque puncta ante vel post missam vtilissime dicenda»)

(26) Ailu Iainkoak nahi halako beharrik ezpaliz, bainan arimako othuruntzatzerik xoilki baliz nolakorik, helas! (SP Imit I 25, 9)

(27) Aitzendu merezi zerbaiten pairatzea Iesus-en izenagatik! (SP Imit II 12, 13)

(28) Hala ere aineza oren erditsu hura bedere behar bezala iragan. (SP Imit IV 1, 4)

(29) Aitzinitzat serbitza ahal bizi naizen egun guziez! (SP Imit III 10, 4)

(30) Iainkoak ailliotsa haren seme maitea gonbidatua lizen eztei guzietara. (SP Phil 38. kap.)

(31) Iainkoak ailliotsa bertuteen aitzinamendua elizen osoki loakartu zure baitan. (SP Imit I 18, 6)

(32) Ailiotsa zure ontasunak nahi sobera hagitz kexa enendin etorkizuneko kasuak gatik. (SP Imit III 39, 1)

(33) Ene kalteak egin nau iakinsun, eta Jainkoak ailiotsa zure ontasunak nahi hala gertatu lizen. (SP Imit III 45, 4)

(34) Ainadilla bada bizi egin merezi eta behar bezala. (SP Imit III 15, 2)

(35) [...] egin ere bedi hala, eta ainadin merezidun gertha. (SP Imit III 56, 4)

(36) Berdin pairatu behar dut, eta aidezadan emeki paira. (SP Imit III 29, 2)

Hegoaldeko testu bakanetan ere lekukotua da ai(t)- optatiboa. Mendebaldean, Garibay eta Perutxoren kantaz geroztik (17)-(18), xviII. mendean beste forma bat aipatu behar da, ei bokalismoaz (37). Forma horren apartekotasuna azpimarkatu beharretan gara, orainaldiko adizki baten gainean eraikia izateagatik. Izan ere, Pouvreau salbuespentzat harturik - puntu honi doakionez bederen haren euskal senaz duda egin liteke; $c f r .10$. oharra-, orainaldiko formetarik abiatu optatibozko adizkien naturaltasuna eztabaidatua izan da (Oyharçabal, 1997: 62, 8. oharra); Mounolek Xviır. mendeko garapen gisa ikusten du (2011: 217). Guztiarekin, beharbada orainalditik abiatu optatibozko formak existitu dira: Pouvreaurenez eta Acto-koaz gainera, Perutxoren kantako ayt joat halakoa dela defendatu dugu (ikus 8. oharra). Bestenaz, XVII. mendeko Nafarroa Garaian agerraldi bat aipa dezakegu (38), $-n$ bukaera duen iraganaldiko aditz batean.

(37) Mari Gabon: Edan eitegi adinon. (Acto 262)

(38) O Cometa Guizonen / Lotzazale bortiza / Ioan aitziñan Turcoaren / Buru cruela guenzera «Fueraste, ò cometa vago / astro espurio a la otomana / cabeza cruel 
tirana / digna solo desde estrago». (Gure Erregue Philippe Andiaren heriotzean 27, in TAV 137) ${ }^{12}$

Zuberoako euskara denaz bezainbatean, ai $(t)$-dun optatiboen agerpena guztiz ezohikoa da. XIX. mendera arte soilik Oihenarten olerkietan eta Noelen Lilian (1782) atzeman dugu halako formarik; Lopezen itzulpena gehiturik, ekialde hertsiko mintzoetan orotara lau adibide ekar dezakegu (39-41). Diferentzia Inchauspek markatzen du: bere idazlan goiztiarretan optatiboaren adibide bakarra eman arren (42), Le verbe basque lanean modu horri ematen dion presentziak bere isla duke geroko ekoizpenean, eta bereziki Imitacionian (44-53). Horrek bide ematen digu pentsatzeko a) optatiboa bereziki presente zela Inchausperen mintzoan; edo b) Inchauspek forma horien aldeko hautu bat egin zuela ${ }^{13}$. Bistan da, Maisterren itzulpenean agiantza eta dolua bestelako adierazpideren bitartez adieraziak dira; $c f r .14 . \& 15$. oharrak.

(39) Egundan ez-ailiz jaio gaxtagina / Ederza, nezkato onaren zegina, / Edo jai -eta, berhala / Hil ailiz, inhar bezala. «Plût au ciel qu'il ne fût jamais né, le scélérat qui fit Beauté servante de Richesse, ou que, à peine né, il se fût éteint, comme une étincelle !» (O Po VI 4)

(40) Sobera guihaur beithan poroança diici otoitzçaren dugun beharras, eta ailira poroança suerte horiec becanago. (AR 97)

(41) Amac Jesus beitaduca / Hersy besouen artian / Bat-bederac baleduca, / Alleduca, alleduca, / Bihoz erdian! (NLilia 9)

(42) Aikunu Mariak bezala begiratu lehen grazia houra! Elas! elas! (Ip Hil 16)

(43) Badakitzat zure egitatiak, etzirela ez hotz ez bero, aizina hotz edo bero! (Ip Apok 3, 11; cfr. Leizarragaren itzulpena, 14. adibidean)

(44) Aikunu egun bat berbera ounxa igaran mundu hountan! (Ip Imit I 23, 2)

(45) Oh! ezpaçunu beharric ez jan, ez edan, ez loic eguin! bena ai-cina bethi Jincoaren laidatzen, eta çoure arimaren espiritualki errekeitatzen! [...] Aikina beharrune horic gabe, eta ezkunu beste arrancuraric arimaren errekeitatzia baicic! (Ip Imit I 25, 9)

(46) Ai-cina cerbaiten sofritzeco houn Jesusen icenagatic! cer ouhouria liçatekian çouretaco! (Ip Imit II 12, 13)

(47) Hortan bacina! Ai-cina heltu çoure cihauren amourioaz bilaiztera, eta ene eta Aitataco eman deiçudan ene Aitaren nahiari çoure buriaren uztera. (Ip Imit III 32, 3)

12 «Un arcaísmo interesante es ioan aitziñan, v. 27, que, con Vinson (quien estampa ailziñan, pero aitziñan en el comentario), hay que interpretar como una forma de "votivo" (“iOjalá hubieras venido!” [...]), aunque de pasado. O ¿̇e tratará de altziñan, de valor equivalente?» (Michelena 1964: 138). Bada, Vinsonek eta Mitxelenak ez bezala, guhaurrek koplaren iturria den 1666ko liburuaren ale baten kontsultatzeko parada izan dugu, New Yorkeko Hispanic Society of America delakoaren liburutegian gordetzen dutena -gaztelaniazko «perifrasia» hortik dugu transkribatu-. Bertan garbiki ailziñan irakur daiteke, baina uste dugu inprentako hutsa dela. Hona Vinsonen iruzkina, ailziñan $\rightarrow$ aitziñan zuzendurik: «aitziñan "puisses-tu être" (ces formes en ai préfixé sont rares dans les dialectes modernes)» (Hovelacque, Picot \& Vinson, 1880: 203).

13 Iduri luke Inchauspek ai(t)- optatiboa ikasia zuela; horren seinale dateke 48. adibideko aicintzaket forma corpuseko -ke dun optatibo bakarra izatea. 
(48) Aicintzaket cerbutza ene menteco egun oroz! ainintz capable egun bakhoitz batez berere, behar beçala çoure cerbutzatzeco! (Ip Imit III 10, 4)

(49) Haur naiçula, coure cerbutzaria, prest nuçu orotara; ezpeiniz nahi bici enetaco, bena bai çouretaco; ainendi ounxa eta çuc merechi beçala! (Ip Imit III 15, 2)

(50) Sofritu beharra badit; aineça pacentziareki, iraçarria igaran artio eta haro houna utzul artio! (Ip Imit III 29, 2) ) $^{14}$

(51) Ikhassi dit ene khostuz; ainitz heben-harat ohartiago eta ez ertzoago! (Ip Imit III $45,4)^{15}$

(52) Eta aineça orano oren erdi houra berere ounxa igaran! (Ip Imit IV 1, 4)

(53) Ainentzaçu coure presentziaz ossoki susta, erra eta cihaurtara khambia! (Ip Imit IV 16, 3)

Orain arteko agerraldi guztiek agerian utzi dutenez, Zuberoan ai(t)- optatiboaren lekukoak oro idatzizko tradizioko idazleak dira. Alderantziz erraiteko, herri antzertiaren tradizioan ez dugu behin ere halako formarik atzeman, eta datu hori oso adierazgarria da. Nolabait, iduri luke zenbait idazlek, zenbait autore jasok, aditzaren joko optatiboaren gaineko kontzientzia atxiki lezaten; kontzientzia horrek halako jarraipena ukan du xx. mendean, ondoko atalean ikusiko denez.

\subsection{Optatiboa Xx. mendeko literaturan}

Garai berrienetan, idazle batek ai(t)-dun optatiboak baliatu baldin baditu, idazle hori Jean Mirande da (54-61); erabili eta, zenbait kasutan, analogiaz sortu ere (61).

(54) Edozein leialtasunen zamaz aileki halaber bere burua askatzen. (Mde Haur 1.)

(55) Lurra eta gizonak gazteago ziren aspaldiko adin horietan ailira bizi izan biok! (Mde Haur 4.)

(56) Ailitz betiko sorgor egon! (Mde Haur 4.)

(57) Zuen bitartez hunki ailitza zorioneko egoitzak Ortzi-Thor edo Akher Beltzari nik dagiodan othoitzak. (Mde «Sanguis Martyrum»)

(58) Ai! goragotik ethorri-haizeek ailezate jo ene landetan et eiharraraz! (Mde «Lili bat»)

(59) Morturik etorri sinesmen arrotza Euskal Herritikan aizinezate ken. (Mde «Euskaldun laminei»)

(60) Aineza gal bizia goiz batez [...] Ainendi hil gazterikan, nihaur. (Mde «Eresi»)

(61) Aineza gal bizia goiz batez / [...] / Aininderor gaztaroan, nerau / ikurriñik et' ikurrik gabe / [...] / Ainitza gal hats, arima, odol. (Mde Po 53)

14 Maister Jinkoak baletsa formulaz zerbitzatzen da pasarte honen itzulpenean: Behar citit segurki soferitu, Jincouac balexa, pacentciareki liçan, iraçarri haur igaren, eta thempora hobe bat jin artio.

15 Hemen ere Maisterrek ets erroa baliatzen du: Ene khostuç hori ikhassi dit, eta Jincouac dexala, eni gogoua haboro har eracitceco den, eta eç erhokeriala eiçteco. 
Mirandez gain, joan den mendeko beste zenbait idazlek optatibozko formarik erabili dute. Eskualduna agerkarian argitaratu zubererazko testu bat izan ezik (62), eta menturaz Etienne Decrepten kasuaz apart (63), ez da dudarik gainerakoak optatiboaren tradizio naturaletik kanpo direla, hots, egile landuen ekoizpenaz ari garela (64-67). Hegoaldeko idazle eta euskaltzale multzo ikasia da, eta haietarik batzuk elkarlan estuan aritu ziren -Zaitegi eta Ibiñagabeitia, kasu; ez ahantz Miranderekiko harremanak ere izan zituztela-.

(62) Eta ailetze ogendünek ororek, beren hütsak aithort, ni orai egitera noan bezain lañoki. (Eskualduna 1913-2-14, apud OEH, s.v. ai-)

(63) Patziku: (hirriz) Ongi zuak, hi bahau atxikitzalle! Xanxiñ: (begiak zerurat) Aileza bertzerik! Behatzalliak hirriz. (Decrept Amatxi 2. zathia)

(64) Iturriñoa bezela ainintz! / mundu otzari igesi. (X. Peña Iturria, OEH)

(65) Oi, naiago berriz ailitzait yoana. (Tapia Perurena, «Neskato utzia»)

(66) Onuntz erakarri gaitun zaldun aitor-seme au ikusi al izatea, Yainkoren batek ai-lizu emango! (Zaitegi Sof 137 (136 ai-nintz), OEH)

(67) Zuen arteko ai-nintza, artzai edo zoritu mats-biltzaile. (Ibiñagabeitia Virgil 63, $O E H)$

Zein helburuz baliatu zuten ai(t)- optatiboa? Jantziago egiteko ote? Badakigu idazle horiek, batzuek behintzat, Iparraldeko tradiziotik edan zutela, -i buruz moldearen erabilpenak erakusten duenez (cfr. OEH, s.v. buru). Halaber, postula daiteke Miranderen lana ezagun zutela; beraz, idazleen arteko eraginen mailako fenomeno baten aitzinean ginateke. Azkenean, Miranderi gorazarre iduri dute idazle zenbaitek azken hamarkadetan idatzi olerkiek $(68-69)^{16}$ :

(68) Baina, ai, ainendi berriz gaztea / Eta aineza neskatila hori ene besoetan! (J. Sarrionandia, Izkiriaturik aurkitu ditudan ener poemak, «Politika»)

(69) Aineza pentsa: dena ez da galdu. Ainendi berriz zure ispilu, bidaztiarena aintzira den bezala. (K. Uribe, Bitartean heldu eskutik, «Urrun izanik»; cfr. Miranderen Eresi olerkia, (60) adibidean)

\subsection{Eremuaz eta iraupenaz}

Zuberoako euskararen deskripzio lanetan ageririk (Oihenart, Chaho, Inchauspe, Belsunce, Gèze, Larrasquet, Casenave-Harigile, Zuazo, Etxegorri, Etxebarne), optatiboa zubereraren ezaugarritzat hartu izan da, nonbait euskalki batuarena bezala. Ikusi denez, ai $(t)$-dun formak egile arkaiko, zahar eta ez hain zaharren ekoizpenean lekukotuak dira, mintzo guztietan. Beraz, ez da dudarik ai $(t)$ - optatiboa behiala hizkuntza osoaren elementua izan zela (Lafon, 1944 I: 73; Zuazo, 1989: 636; Mounole, 2011:

16 Kirmen Uriberen olerkia (69) aski zabaldu da Mikel Urdangarinen bertsio kantatuari esker, eta menturaz horren eragipenaz ainendi forma da Literatura, Antzerkia, Euskara, Gizartea, Sexua, Estintoreak... bigarren izenburu duen blogaren izena: <http://ainendi.blogariak.net/>. 
102). Bestelako kontua da ezaugarri horren egiazko eremuaren garai batean edo bestean definitzea. Testuei lotuz, mendebaldeko euskaran hirutan ageri da optatibozko formarik; nafarrerazko egile batengan, Lapurdiko laurengan eta ekialdeko laurengan (ikus 2. taula). Dena den, ezaugarriaren maiztasuna oso baxua da: XIX. mendera arte, orotara 50 bat agerraldi bildu ahal izan dugu.

2. taula. Optatibozko formen agerpena testuetan.

\begin{tabular}{|c|c|c|c|c|c|c|}
\hline & \multicolumn{4}{|c|}{ Forma perifrastikoak } & \multicolumn{2}{|l|}{ Forma sintetikoak } \\
\hline & \multirow{2}{*}{$\frac{i z a n, " e d u n}{\text { ALEGIA }}$} & \multicolumn{3}{|c|}{ "edin, "ezan } & \multirow[b]{2}{*}{ ALEGIA } & \multirow[b]{2}{*}{ oro } \\
\hline & & ALEGIA & ORAIN & IRAGAN & & \\
\hline Perutxoren k. 1536 & - & - & - & - & ayt joat (ORAIN) & 1 \\
\hline Leizarraga 1571 & - & 3 & - & - & aibintz & 4 \\
\hline Garibay 1591 & - & - & - & - & eiliz (2) & 2 \\
\hline Etxeberri Z. 1627 & - & 1 & - & - & - & 1 \\
\hline Axular 1643 & - & 1 & - & - & ailiotsa & 2 \\
\hline Oihenart 1657 & 2 & - & - & - & - & 2 \\
\hline Pouvreau 1660 & 7 & 2 & 3 & - & $\begin{array}{c}\text { ainintz, aitzine, ailitzaio, } \\
\text { ailiotsa }(4)\end{array}$ & 19 \\
\hline Aleson 1666 & - & - & - & 1 & - & 1 \\
\hline Barrutia 1755 & - & - & 1 & - & - & 1 \\
\hline Lopez 1782 & - & - & - & - & ailira & 1 \\
\hline NLilia 1782 & - & - & - & - & aileduka & 1 \\
\hline Ip Apok 1858 & - & - & - & - & aizina & 1 \\
\hline Ip Imit 1883 & 2 & 4 & - & - & $\begin{array}{l}\text { ainendi, ainintz (2), aizina (2), } \\
\text { aikinalezkunu }\end{array}$ & 13 \\
\hline Ip Hil 1894 & 1 & - & - & - & - & 1 \\
\hline Eskual. 1913-2-14 & - & 1 & - & - & - & 1 \\
\hline Oro & 12 & 12 & 4 & 1 & 22 & 51 \\
\hline Mirande & 2 & 5 & - & - & aileki, aininderor & 9 \\
\hline Decrept & - & 2 & - & - & - & 2 \\
\hline X. Peña & - & - & - & - & ainintz & 1 \\
\hline Tapia Perurena & 1 & - & - & - & - & 1 \\
\hline Zaitegi & 1 & - & - & - & - & 1 \\
\hline Ibiñagabeitia & - & - & - & - & ainintza & 1 \\
\hline Oro & 4 & 7 & - & - & 4 & 15 \\
\hline
\end{tabular}

Menturaz, optatiboak egiazki noiz arte iraun duen ebaztea da punturik zailena. Testu zaharrak oro bil, ikusi dugu horren maiztasuna ez dela batere handi eta, gehiago dena, Zuberoan biziki agerraldi gutxi atzeman daitekeela -Lapurdin baino anitzez gutxiago, Inchauspe alde batera utzirik behintzat-. Oyharçabalen erremarkari lotuz (1997: 56), zergatik Tartasek, Belapeirek edo Maisterrek ez zuten behin ere ai(t)-dun formarik erabili? 
Eta zergatik herri antzertiko lanetan ez dugu behin ere aurkitu? Ezen, bada halako kontrastea gramatikagileek deskribatu paradigmen eta testuen lekukotza bakanaren artean. Guztiarekin ere, agerraldi natural berankorrenak ekialdeko testuei dagozkie.

Pentsa dezakegu XVII edo XVIII. menderako ai $(t)$ - optatiboa ihartua zela, edo bederen ez zela aski erabiltzen, hizkuntzak bestelako bideak baitzituen igurikimen eta desioen adierazteko. Mounoleren azterketan, XV. eta XVI. mendeetan forma horiek "peu nombreuses» dira (2011: 102): XVIII. mendean Barrutiaren etsenplua baizik ez du biltzen, eta XIX. mendean «[elles] ne semblent exister qu'en souletin [...], et selon le témoignage de Videgain (ap. Oyharçabal, $1987: 512$, note 1), elles étaient toujours usitées au $20^{\text {ème }}$ siècle, du moins dans certaines variétés de ce parler» (2011: 218). Beraz, XIX. mendean optatiboa soilik Zuberoan erabiltzen zen: «Temps n'appartenant qu'au dialecte souletin» (Bonaparte, 1869 II: $8 \&$ hb). Oyharçabalentzat, Chahoren gramatikako lekukotasuna garrantzi bizikoa da, ai $(t)$-dun formak ahozko mintzairatik ezagut baitzitzakeen (1997: 56).

xx. mendean, Gavel eta Lacomberentzat «[L'optatif] n'est plus employé en labourdin, mais n'a pas complètement disparu du souletin» (1937: 48). Lafitteren gramatikan optatiboak «archaïque» etiketa darama (2008 [1944]: \$§ 640 \& 642); «Tout cela n'existe plus qu'en Soule» (ibid.: § 722). Eta Lafonek iraungitzat ematen du: «En souletin actuel, les formes de votif ne sont plus employées : elles ne figurent pas dans les tableaux de formes verbales du Basque Souletin Nord-Oriental de M. J. Larrasquet. Aucun des Souletins que j'ai interrogés ne les emploie ni ne les connaît» (1944 I: 495). Orobat ondorioztatzen du Clément de Jaureguiberry zuberotarrak: «Le votif dont le chanoine Inchauspe donne la conjugaison complète semble s'être perdu en Soule dans ces 100 dernières années» (1957: 76).

Aldiz, Casenave-Harigileren oharretarik idokitzen ahal da ai $(t)$ - moldeko formak xx. mendean erabili direla, eta santagraztarrak bere bizian entzunak dituzkeela ${ }^{17}$. Berrikiago, Etxegorrirentzat «Eskiula eta Jeruntzen zubereraren egiazko opazkoa entzun omen daiteke» (2003: 269), eta ondoko lan batean omenka aritzeari uzten dio: «Eskiulako aldean opazkoak bizirik dirau. Oso hedapen txikia dauka zaharkeria [sic] honek, ez baita Barkoxera ere heltzen! Erabilpen arruntak Jeruntzen eta Eskiulako herri barnan jaso ditut. Orainaldian: ailedi mintza! 'mintzatuko ahal da!', aileza ikus! 'ikusiko ahal du!'. Iraganaldian: ailitz mintzatü! 'mintzatuko ahal zen!', ailü ikusi! 'ikusiko ahal zuen!'» (2007: 75-76). Beraz, testigantza desberdinak plazaratu badira ere, klarki ezar daiteke guztiz iraungi arte, euskararen optatibo zaharrak Zuberoan iraun duela berantenez.

17 «Aizinae \& aizintee: ahozkoa aiziné, aizinté (azkardüra azken hizkian)» (Casenave-Harigile, 1993: 492); «aitzintzeitae: mintzatzean, entzüten da ere: aitzintzeiztae» (ibid.: 507. or.). 


\section{5. $A i(t)$ - aurrizkiaren jatorriaz}

Optatibozko ai $(t)$ - aurrizkiak badu ei(t)- alomorfoa mendebaldean. Mounolerentzat alomorfo horren eta ei partikula modalaren jatorria bat eta bera dirateke: "Il se pourrait fortement que cette particule adverbiale et le préfixe de votif $e i$ - soient d'origine commune» (2011: 101). Lotura egiantzekoa izan arren, ai $(t)$ - optatibozko aurrizkiak badu partikulartasun bat, ezen aditzari eranstean aldaketa fonetikoak eragiten baititu: aiginte \& aizinte baino maizago aikinte \& aitzinte bezalakoak aurkitzen ditugu ${ }^{18} ; \mathrm{Ba}-$ rrutiaren etsenpluan ere $t$-dun aldaera datza: edan eitegi (= "aiteza).

Perutxoren kantako ayt joat formaz landara (18), XVI. mendeko testuetan ait- bakarra genuke: Leizarragaren aitzinezate (13), Lafonendako optatibozko formen aurrizkia aitdela suposaraz lezakeena -halere, bait- eta albait- aurrizkidun formekiko analogiaren esplikabidea hobetsi zuen (1944 I: 495)-. Zehaztu behar da $t$-dun aldaeraren agerraldi bakar hori isla grafiko posiblea duen testuinguruaren agerraldi bakarrari doakiola; hots, $t$ ager zitekeen kasu bakarrean ageri dela, zeren hintz, litez edo nenzazue formei lotzean, ait- aurrizkiak $t$ galduko bailuke, bait- aurrizkiak galtzen duen bezala. Beraz, Leizarragaren aitzinezate ez litzateke salbuespen, arau morfonologikoaren grafikoki islatzeko aukera bakarraren agerpena baizik.

Bestalde, ikusi dugunez, ondoko mendeetan $t$-dun formak nagusi dira. 3. taulak ai(t)aurrizkiaren agerpen $t$-dun zein gabea jasotzen du, $t$ horren isla grafikoa posible den inguruneetan. Orotara $t$ gabeko zazpi etsenplu baizik ez dezakegu ekar, haietarik bi Pouvreaurenak, eta gainerako bostak Inchausperenak -egile horiek kontrakoa ere lekukotzen dute-. Halaber, beste bi datuk aurrizkiaren forma ait- delako hipotesiaren alde egiten dute: bata, 1536koa den Perutxoren kantan ayt joat agertzea (18), eta bestea Etxeberri Ziburukoak aitnetza forma ematea, menturaz grafia etimologikoz (19). Aurrizkia, beraz, ait- da garbiki, eta ez ai-: lekukotasunek hala bermatzen dute, kuantitatiboki ere, nahiz eta OEHk dioen «La forma ai- predomina claramente sobre ait» (s.v. ai (t)).

18 Chahok aïkina, aïkunu, aïtzuntu zein aïzina \& aïzunu jasotzen ditu (1836: 158). Inchausperen (1858: 106113) eta Gèzeren (1873: $95 \&$ 123-124) tauletan aldaketa fonetikoak sistematikoak dira. Bonapartek hori du esplizitatzen: "Cette syllabe ai peut produire en outre des changements initials [sic]» (1869 II: 158). Egungo Zuberoan Casenave-Harigilek $t$ gabeko formak ematen ditu (1993: 492, 507, 522 \& 535), salbu 2. pertsonako aitz- afrikatu zenbait. Azkenik, Etxebarnek aiginalaikina aukerak ematen ditu (2011: 7. taula). 
3. taula. ait- aurrizkiaren $t$ edo haren eraginpeko aldaketa fonetikoen lekukotza, beroiek agerraraz ditzaketen inguruneetan.

\begin{tabular}{|c|c|c|}
\hline \multicolumn{3}{|c|}{$t$-dunak } \\
\hline Leizarraga & aitzinezate & \\
\hline Pouvreau & $\begin{array}{l}\text { aitzine }(22) \\
\text { aitzendu }(27) \\
\text { aitzinitzat (29) }\end{array}$ & $\begin{array}{l}\text { aigine (21) } \\
\text { aidezadan (36) }\end{array}$ \\
\hline Aleson & aitziñan (37) & \\
\hline Barrutia & eitegi (37) & \\
\hline Inchauspe & $\begin{array}{l}\text { aikunu (42 \& 44) } \\
\text { aikina (45) }\end{array}$ & $\begin{array}{l}\text { aizina }(43,45,46 \& 47) \\
\text { aizintzaket }(48)\end{array}$ \\
\hline
\end{tabular}

Zer ote datza ai(t)- aurrizkiaren jatorrian? Guk dakigula, lehenbiziko hipotesia Van Eysena izan zen, ai aurrizkia adi batetik eratorririk ${ }^{19}$ (1879: 233). Lafonek ai auhenezko partikula zekusan, $t$-dun formak analogiaz azalduz:

Ai existe comme interjection marquant la douleur (Azkue) et aussi la surprise (Lhande). Sans doute le ai- des formes de votif et des expressions telles que ai baletor était-il originairement identique à l'interjection, et celle-ci a-t-elle été réservée par la suite à l'expression de la douleur et de la surprise. En tout cas, ce n'est pas à cet ai- que les formes de votif doivent leur valeur modale, mais au fait qu'elles sont des formes du second groupe exprimant l'éventualité. Ai, quelle que soit son origine, ne servait sans doute d'abord, comme albait- dans les formes dites de prescriptif, qu'à préciser la valeur de la forme verbale à laquelle il était joint. [...] L'équivalence de soul. banéki ! et de guip. et bisc. ai baneki montre que le préfixe des formes de votif n'avait à l'origine qu'une valeur d'appoint (1944 I: 495).

Lafonek eta Oyharçabalek (1997: 57) proposatu analogia baztertu gabe, beste aukera da pentsatzea optatiboaren ait- aurrizkia bait-etik etor litekeela. Hipotesi hori mendebaldeko datuekin zerbait korapilatzen da, ezen eit- aldaeraren bokalismoa ez baitator Lafonek (1944: 485) eta Lakarrak (1986: 655-656) bizkaiera zaharrarentzat deskribatu duten bai(s)t- aurrizkiarekin bat. Hipotesiaren alde, mendebaldeko eit- aldaerak eta $e i$ partikula modalak balio desberdinak dituzte. Ekialdeari begira, ait- eta bait- aurrizkien arteko loturak koherente dirudi: Zuberoako beit- aldaera berria da, optatiboa emankor egon zitekeen garaietan testuek bait- ematen dutelarik ${ }^{20}$.

19 «Ai pour adi pourrait avoir pris la valeur d'un impératif "puisse" \& plutôt en français "veuille" ; ai-nintz signifierait alors : "veuille que je fusse”, c'est-à-dire : "puisse-je”. Nintz est la flexion syncopée pour nintzake, imparfait de l'optatif (aujourd'hui conditionnel) de izan» (Van Eys, 1897: 233).

20 Zuberoako testu zaharrenetan bait- baizik ez da ageri (Oihenart, Zalgize, Etchart); Tartas eta Belapeirerengan bait- da ohikoena, eta beit- han-hemenka azaleratzen da. Aldaketa XVIII. mendean gauzatuko da: 1734 ko Othoitce testutik aitzina bi aldaeren arteko proportzioa ifrentzikatzen da, eta xIx. mendean baitdesagertzen da beit- berriaren faboretan. 
Euskararen optatiboaren baliabide morfologikoa aurrizki bat izatea guztiz nabarmentzekoa iruditzen zaigu, horrek garai zahar batera igortzen baitu. Izan ere, hizkuntzaren aurrizki bizi bakanetakoa izan da ai(t)-, aditz morfologiaren beste gutxi batzuekin batean: $b a-, b-, l-, d$ - edo bait- bera. Bistan denez, ait- moldea mintzo guztietan lekukotu izanak ere garai zahar horri begira paratzen gaitu, hots, zatiketa dialektala baino lehenagoko hizkuntza egoerari.

Ikuspegi tipologikotik, optatiboaren gramatikalizazio bideak definitzea zail gertatzen da. Agintera hizkuntza gehientsuenetan existitzen da, baina igorleari orientatutako gainerako modalitateak -erran nahi baita optatiboa, hortatiboa, prohibitiboa edo admonitiboa- anitzez bakanagoak dira, eta horrek aski zailtzen du halako hipotesien formulatzea (Bybee, Perkins \& Pagliuca, 1994: 211). Haatik, pentsa daiteke optatiboaren gramatikalizazio bideak geroaldia, baldintza, subjuntiboa eta agintera direla (Sadock \& Zwicky, 1985: 164); ikuspegi zabalagotik, hainbat hizkuntzatan egitura desideratiboek geroaldia, helburua edo beharra ere adierazten ahal dute (Musi, 2016). Gauzak horrela, morfologiaren aldetik postula genezakeen *(b)ait- aurrizkiak balio horietako bat adierazi behar zukeen Euskara Batu Zaharrean. Horri lotuz, ez da komeni ahanztea historikoki bait- aurrizkiak baldintzazko balioa ere hartu duela ${ }^{21}$.

Munduko hizkuntzei soño bat eginez, badirudi zenbait kasutan optatiboa ezaugarri areala dela, edo hizkuntz ukipenaren ondorioa. Hala nepalieraren nola Kaukasoko bi hizkuntza turkikoren optatiboak inguruko hizkuntzen eragina izan litezkeen bezala ${ }^{22}$, menturaz guk azalbide horren ifrentzutik begira genezake euskararen optatiboaren galera. Hau da, euskara hein batean modelatu duten erromantzeek optatiboa peitu izateak ez duke hizkuntza hartzailea den euskarak kategoria hori atxikitzen lagundu. Aldiz, azken mendeetan optatibo zaharra ordezkatu duten egitura gehienek (§3) paraleloak dituzte inguruko erdaretan; are gehiago, haietarik batzuk mailegatuak dira.

21 «In some texts bait-is used instead of the more usual conditional morpheme ba-. This is most frequent in Axular and Maister (but attested also in Aranbillaga, Gasteluzar, Pouvreau, Etxeberri Ziburukoa, Beriain and Belapeire). Even though present tense verbs can also take the conditional bait-, it is particularly common with hypothetical verb forms and especially in the expression bait- ... bezala 'as if...' (Krajewska, 2016: 261); cfr. OEH, s.v. bait-. Lafonek, halere, ez du bait- ... bezala baldintza gisa analizatzen: «La construction employée par Axular s'explique aisément. Les formes à préfixe bait- équivalent parfois à des formes relatives ou à des formes à suffixe -la indiquant la manière ou les circonstances. Les formes d'éventuel à préfixe bait- employées par Axular ont une valeur analogue. Combinées à bezala [...], elles signifient littéralement 'comme quelque chose que vous auriez à vous, fait par vous' [zeurea, zeure egina baitzendu bezala], 'comme qui aurait parlé au cordonnier' [zapataginarekin berarekin mintzo izan bailliz bezala]" (1966: 227). Beste maila batean, bait-aurrizkia albait- preskriptibo zaharraren osagai morfologikoa da, eta ala bait- harridura edo auhenezko egituraren parte ere.

22 "Whether the Caucasian optative is a phenomenon due to areal contact or to a common origin is not clear, in part because the genetic affinity of the Northwest and Northeast languages is still under discussion. Interestingly, both Turkic languages of the Caucasus, Karachay-Balkar and Kumyk, have a full personal paradigm of a morphologically dedicated optative, which is untypical of Turkic. A second area that seems to be characterized by the morphological optative is northern India and Nepal. The optative occurs in some of the Tibeto-Burman and Munda languages, and interestingly, the only Indo-Iranian language we found to have a morphological optative is Nepali (Korolev 1965: 80), probably as a result of the influence of neighboring Tibeto-Burman languages» (Dobrushina, Van der Auwera \& Goussev, 2013). 


\section{IGURIKIMEN ETA DESIOAREN BESTELAKO ADIERAZPIDEAK}

Betiere esperantzaren eta desioaren adierazpenaren eremuan, atal honetan euskaraz optatiboaz landara baliatu izan diren aukera morfosintaktikoak laburzki azterkatuko dira, ekialdeko euskalkien lekukoei lehentasuna emanez. Oro har, mendebaldean zein ekialdean, agiantzaren eta doluaren adierazpideen iturriak ohikoak dira munduko hizkuntzetan:

a) Baldintzazko egiturak: ba- aurrizkia, alba- aurrizki konplexua, balinba partikula -jatorrian baldintzazkoa- edo aments ba- egitura.

b) Aginterazko egiturak, euskararen kasuan jusiboak: Jainkoak detsala, Jainkoari nahi dakiola, besteak beste ${ }^{23}$; hemen, arrazoi pragmatikoengatik, «Jainkoari lotutako formulak» etiketa pean bilduko dira.

c) Geroaldiko perpausak: [PART. PROSPEKTIBOA + ahal] egitura.

\subsection{Ba- aurrizkia}

Baldintzazko protasiek hipotesiaz kanpoko balioak har ditzakete, hala nola igurikimen eta desiraren adierazpena. Halako egituretan, perpaus nagusiaren ezabatzea ohikoa da munduko hizkuntzetan, insubordination deitua den prozesuaren medioz. Landucciok oxala = validi baliokidetza argigarria dakar (299 apud Mounole, 2011: 102). Optatibozko formen baldintzazkoez ordezkatzea, beraz, gauza ohikoa da. Lafittek (2008 [1944]: § 721), ba-aurrizkiaren balioez ari, éventuel delakoari estekatzen dio; baldintzaz landara (supposition), konpletiboa ere adieraz dezake (nabi nuke jin baladi), bai eta desira. Lafittek balio desberdinak esleitzen dizkie aldiei $(c f r . \S 1.1$ ataleko azalpen orokorra):

Il faut bien distinguer entre l'optatif de futur (potentiel), qui marque un vrai souhait (Ah! Ethor baledi! Ah! Plaise à Dieu qu'il vienne !), et l'optatif du présent ou du passé (irréel), qui exprime le regret (Hemen balitz Que n'est-il ici !, Leher egin balu Que n'a-til crevé !, Bere eginbidea bethetzen balu Que ne fait-il son devoir !). L'éventuel des verbes forts ne marque que le regret (Banaki! Si je savais ! -mais je ne sais pas-) (idem).

Zuberoako testuetan ez da horren adibiderik falta (70-72); Lafittek erremarkatu desberdintasuna -agiantza $v$ s. dolua- hauteman daiteke Jokastaren (71) edo Elisabeth erregina santaren (72) auhenetan.

23 Lan honetan aztertzen ez dugun bestelako egiturarik ere aginterazkoen sailean sartzeko da, hala nola Lekeitioko euskaran deskribatu den formula desideratiboa: Etxera joatea daukala! (jutia daukola) (Hualde \& Ortiz de Urbina, 2003: 296-297. or.); jusiboa izateaz gainera, jutia daukola formak ahalerazko balioa du. 
(70) O Jesus crucificatu içan dena, goure bihotciala jin baledi; ala beikintçake bertan ikhas, gaiça jakin behar dutugunak oro! (Mst I 25, 6)

(71) Secula ikhousy ezpanu, / oh crudel destinatia! / Maradicatu da enetaco / sorthu nintçan mementoua. / Arguy gabe içan baliz / ny sorthu ninçan eguna / edo sabelian ninçala / hil baliz ene ama! (Edipa 92-93)

(72) Ene haurren artian / possible baliz unionia! / Ah, othoi lagunt neçaçu, / ene salbaçale maitia! (SteEli 1220)

\subsection{Ai ba- egitura}

Auhenaz gainera, ai interjekzioak desioa ere adieraz dezake: «ai baletor 'plût au ciel qu'il vînt !' et aineki 'plût au ciel que je le susse !', qui peuvent être simplement 'oh ! s'il venait !', 'oh ! si je le savais !'» (Lafon, 1944 I: 495); interjekzio horren eta ai(t)- aurrizkiaren arteko loturarentzat, ikus $\S 2.5$. OEHren hitzetan, «En oraciones con el verbo en modo hipotético, exclamación que expresa un deseo irrealizable» (s.v. ai 1). Ai baegituraren adigarri, OEHk mendebaldeko idazleak dakartza XVIII. mendetik -Aguirre Asteasukoa, Mogeldarrak, Lardizabal edo Arrese Beitia, besteak beste-, eta Xx. mende hastapenetik aitzina ekialdekoak ere (75-78). Zuberoan ez dugu molde horren agerraldirik aurkitu, baina bai ah! interjekzioarekikoarenik (79-81):

(73) Ai! eta baziñaki, nolako perillean zauden! (AA III 498)

(74) Ai baleude aitatu ditudan bezelako jakitunak! (VMg 90)

(75) ‥ nik ere, bai, banik / hik dukan gozoa! (Zby RIEV 1908, 769)

(76) $\underline{\text { Ai }}$, balute bazterretan aste guzia lanarekin borroka bizi diren gizon nekatzale guziek beren etxean zu bezalako emazte bat. (HU Zez 185)

(77) Aii! Maria, Maria! Oihanburuan egon bahintz, hire xokoñoan! (Barb Sup 85)

(78) Ai orok mihi hori bridatzen balute! (Etcham 144)

(79) Ah cerbutcha ahal bacintçat ene menteco egun oroç! (Mst III 10, 4)

(80) Gogouan erabilten niçun, / a h, çu jçan bacina! (Chiveroua eta Marceline 248, in Urkizu, 1998: 147)

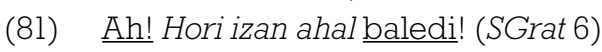

\subsection{Aments ba- egitura}

XVIII. mendeko Zuberoan aments aditzondoa $b a$-aurrizkidun formekin konbinatua azaleratzen da, desirazko balioaz. Egitura horrek paralelo ezagunak ditu inguruko erdaretan, eta harago; $c f r$. fr. [si au moins/ seulement + sUBJ], esp. [si al menos + sUBJ], ing. [if only + suBJ] edo errus. [если бы только + sUBJ], besteren artean. Aments aditzondoa gaskoiari mailegatu zaio ( $\leftarrow$ au ments), eta Zuberoan zein Nafarroa Behereko ekialdean erabiltzen da. (82-85) adibideetan hauteman daitekeenez, aments ba- batez ere dolu edo erregretaren adierazpenari lotua ageri da. Mendebaldean, sikiera ba- molde baliokidea lekukotzen da $(O E H, s . v$. $)$.

(82) Alo, Julien, erran bahu amenx / emazte gaiztouc senhar gaistoury beçala: / «preparady guero behar tugun / horien emaitera» (StJul 632) 
(83) Ah Olimpia, ala nic beitutut / sofritcen phena handiac, / amenx ezpalirade / bataillan ene semiac. (Edipa 424)

(84) Sendo eracy ahal banitça / jhourq jkhousy gabe / amenx berrien sortceko / ounxa sendo balite. (Boubane eta Chilloberde 9, in Urkizu, 1998: 107)

(85) Amenx ezpaledi gin orano eraunxi hori! (SGrat 8)

\subsection{Alba-aurrizki konposatua}

Alba- aurrizkia desioen adierazpeneko beste aukera da (ahal $+b a-)$. Lafonek «potentiel de suppositif» gisara sailkatu zituen alba-dun formak, zeinen artean alegiazkoek «peuvent servir à exprimer un désir, un souhait, un regret» (1944 I: 477). Euskara arkaikoari doakionean, Mounolek Etxeparerengan baizik ez du lekukotu (2011: 102), eta beranduago $1729 \mathrm{koa}$ den nafarrerazko lehen predikuan (ibid.: 218. or.). Leizarragak ere alba- ematen du, baina orainaldian. Ondoko mendeetarako EKCk datu interesgarriak eskaintzen ditu, zeinetarik hautapen bat baitakargu (86-98). Ohart bedi zenbait adierazpideren konbinazioez: doluzko helas + alba- (86), auhenezko o/ oil ai + alba- (90, 93, 94 \& 97), eta desirazko oxala + alba- (95).

(86) Elas yzul albaneça yraganden denbora. «Ah! si je pouvais faire revenir le temps passé» (E VI 21)

(87) Albanerra eguya nyc dut pena handia (E IX 47) ${ }^{24}$

(88) Ordean satisfatçeco ossoqui gutitia / Badut, obran albaneça eman neure nahia. (EZ Man II 75)

(89) Hura handi den arauaz, / Nic solas albanegui. (Hm 83)

(90) Oi eta atera albanegiz beren lekutik Señora oni beardanezko koroe bat egiteko! [...] Oi eta albanegi oñazpikotzat ezarri aren oñazpietan! [...] Oi eta zeure argierrañuetatik epaki albanegio geure Ama mindun oni manturik ederrena! (Lar SermAzc)

(91) Milla bizi, albanitu, nik zugatik [...] (Cb Eg II)

(92) Albanei ni or egon joateko paseatzera atso ura eztegu erango bakarrik joan bear gara. (Gamiz)

(93) O albanezkike erran bear den bekala uskaras sanduaren itzak! (LE Urt «Serm. 5. De peccato, ut contra Deum. ann. 1771»)

(94) O urtu albanegiz ene begietako negarrakaz leen eginak! (Añ EL)

(95) Ojala itzegin albaneza nik gai andi onek eskatzen duan eran! (AA III)

(96) Sendatu albazentza nik daukadan miña, nere biotz gaixoak a zer atsegiña! (Izt Po)

(97) A paper ontan gogo detana albanezaioke jarri! (EA NereB)

(98) Urtiak baduazi, urratsik eztager, Non galtzen dira-edo? Albaneukaz uler! (Laux $\mathrm{BBa})$

24 «Il est difficile de dire si ce vers se compose de deux phrases dont l'une exprime un souhait (si je pouvais dire la vérité !) et l'autre une réalité, ou s'il forme une phrase dont le second membre exprime ce que dirait celui qui parle si la condition énoncée dans le premier était réalisée» (Lafon, 1944 I: 478). 
Goiko adibide sortak erakusten duenez, bakarrik alegiazko formekin alba- ekialdeko behe-nafarrera arkaikotik bizkaiera modernoraino lekukotua da, lapurtera, nafarrera, arabera eta gipuzkeratik iraganez; aldiz, Zuberoako testuetan ez dugu haren herexarik ediren. Lafonek alba-aurrizki konplexua dialekto guztietan existitu izanaz duda egin zuen (ibid.: 478. or.), eta Oyharçabalentzat Hegoaldeko testuetako alba ez litzateke aurrizki bat, bi morfemen metatzea baizik ${ }^{25}$. Hala ere, nahi bada, Hegoaldeko alba- segidak Iparraldeko alba- aurrizkiak adieraz ditzakeen balio berak adieraz ditzake, tartean desirarena, baina batzuetan balio horiek ez dira aise bereizten ahal; $c f r$. 87. adibidea eta bertako oharra.

\subsection{Balinba partikula}

Menturazko balioaz gain ( $c f r$. OEH s.v. baldinba), balinba edo balima partikulak agiantza ere adieraz dezake, betiere indikatibozko perpausetan. Horren erranahia: «Interj. exprimant un souhait ardent» (VocBN apud OEH); "Exclamation de désir, d'espérance» (Gèze, 1873: 242); «Exclamation de désir, d'espérance, d'imprécation» (Ithurry, 1895: 362); «Synonyme de oxala (esp. oxala, ojala!) plaise à Dieu» (Haritschelhar, 1969: 386). Ithurryrentzat, Leizarragak eta Axularrek desirazko balioaz erabili zuten bal(d)inba (99-100) ${ }^{26}$ :

(99) Eta orain ichilic campora egoizten gaituzte? ez balimba: baina beréc ethorriric idoqui gaitzate. 'Plaise à Dieu que non' (Lç Act 16, 37)

(100) Baldinba ez ahal naiz hunen gatik ifernurako 'Il faut espérer que je n'irai pas en enfer pour ceci' (Ax 57 apud Ithurry, 1895: 362) $)^{27}$

OEHn balinba lekukotzen duten testuen artean badira Zuberoakoak (Maister, Xarlem, Mustafa, Chants Populaires eta Etchahun) nahiz Akitaniako gainerako euskal herrietakoak: Gazteluzar, Hiribarren, Laphitz, Hiriart-Urruthy, Zalduby, J. Etchepare eta Barbier. Hegoaldean xx. mendeko bi idazle ikasi lekuko dugu: Goikoetxea Gaztelu eta K. Mitxelena. Balinba desirazkoaren lehenbiziko agerraldia Axularrena bada (100), ekialdean, gisa guztiz, xviII. mendean hasten da hedatzen. Gure corpusean Maisterrengandik ageri da, eta bereziki herri tradizioko testuetan (101-107).

25 Hona arrazoia: «Ez Leizarragak ez Etxeparek ez dute sekula silaba bakarreko eta aspiraziorik gabeko formarik erabiltzen ahal adierazteko, salbu alba- morfoarekin»; ezezko formarik lekukoturik bageneza, ez non agertuko zen ikusirik afera trenkatzen ahalko genuke, baina ez dugu horrelakorik (Oyharçabal, 1997: 47). Alabaina guretzat, Iparraldekoek ahal partikularen bi itxura fonologiko diferentetan emateak alba- aurrizkia dela bermatzen duela onarturik ere, horrek ez du kentzen Hegoaldeko testuetan ere -kasu batzuetan bederen-alba- aurrizki izatea zeren, hasperena galdurik, Hegoaldekoek ez baitzezaketen halako bereizkuntza grafikorik egin.

26 Alta, gure ustez ez da batere segur Leizarragarenak balio hori adieraz dezan. OEHk bi adieratan jasotzen du Leizarragaren balimba hori: lehenbizi «ciertamente; seguramente» erran-nahiaz: «In [sic] ne sera point ainsi» (s.v. baldinba 1), eta ondoren balio desideratiboz, Ithurryren itzulpenarekin: «Plaise à Dieu que non» (s.v. baldinba 2).

27 Egiazki, Axularrek honela dio: Baldinba, ez ahal naiz hunengatik, bunein gauza aphurragatik, eta bunein erraxki egin dudanagatik ifernurako? 
(101) Eçtuçu balimba ihessiric eguinen çoure arimari hagnbeste abantalla ukhen eraci ahal dirouan iracourte baliousari. (Mst xx)

(102) Comfidancha handireky / dut othoycia eguinen, / eta balinba Gincouac / benay ençunen. (StJul 1146)

(103) Balima batailla hountan / biçia du galduren / haren plaça niq beitut / aspaldian desiratçen. (Xarlem 1288)

(104) Hoxt guitian arren, / isseiatu nahi nuçu; / eta hara artino / balima helturen nuçu. (SteEli 1233)

(105) Çaude errephausuqui, anderia, / eztuçu çure aldi. / Ez ahal ceiçu balinba / guibelturen engoiti. (Malqu eta Malqulina 555, in Urkizu, 1998: 263)

(106) Balinba zure gaitza etzüzün, gaixua, / Arauz gaierditako zerena gaxtua. 'J'espère'. (Etch 376).

(107) Esker deiçut, Ama houna, çoure eracouspenez. Balinba çoure exenpliec phitzeraciren naic. (MaiMarHil 71)

\subsection{Oxala partikula}

Esperantza eta desiraren beste adierazpide bat dugu oxala, Penintsulako erromantzeei mailegatua, eta azken buruan Espainiako arabieratik datorrena (<law šá lláb 'Jainkoak nahi badu'). Mounolek 1729ko nafarrezko predikuan (108) eta Urteren gramatikan atzeman du (2011: 218); haren arabera, hurrengo mendeetan oxala esperantza eta desioen adierazpide nagusi bihurtuko da. Lafitteren ustez, egile modernoek sartu dute «Pour distinguer le si conditionnel du si votif» (2008 [1944]: § 722). Zuberoako testuek ez dute oxala lekukotzen ${ }^{28}$, eta behe-nafarreran ere ez bide da sartu, bederen EKCren emaitzei begiratuta. Oyharçabalek ohartarazi bezala (1997: 57), Leizarragak (14) -eta harekin Inchauspek (43) - ai(t)- optatiboa baliatzen duen pasartean Haranederrek oxala darabil (108). Ondoko bi adibideetan oxala partikula jusibozko forma batekin eta $b a$ - aurrizkiarekin erabilia da, hurrenez hurren:

(108) Ojala estaiela arla izan (Lehenbiziko sermoia nafarreraz 7)

(109) Badaquizquit çure eguitateac. ez çaretela ez hotz, ez bero. Ochala hotza baçiñe edo beroa. (He Apok 3, 15)

\subsection{Abal partikula}

Ezaguna da mendebaldeko euskaretan ahal partikula balio desideratiboz erabiltzen dela, partizipio prospektiboarekiko egituran (Zubiri \& Zubiri, 2000: 578; Euskaltzaindia, 2002: 445; Hualde \& Ortiz de Urbina, 2003: 315 $)^{29}$. Molde horren lehen agerraldia XVII. mendekoa dateke (110). OEHk ondokoetan ere lekukotzen du: Urquizu (111),

28 Anekdotikoa bada ere, Etxebarnek «Opazko (Oxala!)» baliokidetza dakar (2011: 7. taula).

29 Desirazko ahal eta galderazko al partikulak jatorri berekoak dira (< ahal). Bigarrena Gipuzkoan kokatzen da (Zubiri \& Zubiri, 2000: 578), eta estandarizazioarekin hedatzen ari dateke (Jendraschek 2003: 269). Euskara batuan ahal / al grafiek bi balioak bereizten dituzte. 
Larramendi (112), Cardaberaz, Larreguy (113), J. A. Mogel, Aguirre Asteasukoa, J. J. Mogel, Hiribarren (114), Duvoisin (115), Elicegui, Soroa, Arrese Beitia eta Mocoroa.

(110) Laster etorri nadin guraco aldoçu (ConTAV§ 5.1.4) $)^{30}$

(111) Nunbaita orain amaituko al dau / bere betiko egarriia. (Urqz 82)

(112) Agur, Aita nerea, ta gogoango al nazu zure otoitzetan. (Lar, carta a Mb 281)

(113) O! zuek egia erdiragarri hauk irakurtzen eta entzuten ditutzuenak, sarthuko ahal zarete zuen baitan. (Lg II 191s)

(114) Ez ahal du sekulan yauna ahantziko. (Hb Esk 237)

(115) «Emanen ahalko daut ene saria, 'puisse-t-il me donner ma récompense'. Ici le sens optatif du basque ne peut être rendu en français» (Dv apud OEH, s.v. ahal)

Beraz, XIX. mende inguruan [PART. PROSPEKTIBO + ahal] egitura desideratiboa Lapurdin ere lekukotzen hasten da (113-115). Ekialderago, madarikazio batean atzeman dugu, 1807an datatua den fartsa batean (116); halere, ez da komeni ahanztea Zuberoan egitura horren baliorik ohikoena geroaldiko ahalera dela $(117-119)^{31}$.

(116) Khurutçhia deitaqua orai / eni aiphatçen heben? / Larria elkhiren ahal çeiq / etçhera beno lehen. (Malqu eta Malqulina 430, in Urkizu, 1998: 253)

(117) Enganatuko bide zira / gaurger', orano bezala, / baduz' uste zure begira / Egonen ahal nizala, / Hautuagorik zu bano / deiez ondotik dautano. 'Vous vous tromperez sans doute si vous croyez qu'à l'avenir je pourrai, comme je l'ai fait jusqu'à présent, rester à vous attendre pendant que de plus distinguées que vous m'invitent à les suivre' (O Po XXIII 2)

(118) Jesus çoureki bada, exayec batec ere eçteiçu oguenic eguinen ahal. (Mst II 8, 2)

(119) Badabila cien ungurian lion bat orrouatuz beçala, tcherkhatuz çougn iretxico ahal dian. (Urruty Epit I 5, 8)

Bestenaz, Akitaniako euskaran desirazko ahal partizipio prospektiboarekiko egituratik kanpo ager daiteke, galderazko perpausetan: «La particule ahal placée entre la négation $e z$ ou encore l'affirmation $b a$ et la forme personnelle du verbe donne à la phrase une nuance d'interrogation rassurée à sens optatif. Ex. : Ez ahal nute ikusi ? Ils ne m'ont as vu, j'espère ? Ba ahal da bertze holako joiarik? Il y a bien, je pense, d'autres perles de ce genre ?» (Lafitte, 2008 [1944]: § 222). Zuberoan ez dugu usadio horren lekukorik.

30 «No nos parece correcta la traducción de Satrústegui, que da a al un valor interrogativo, valor que sólo toma dicha partícula en guipuzcoano y en textos más modernos. Nos inclinamos por darle un valor desiderativo, con el sentido de la estrofa» (Sarasola, 1983: 89-90).

31 Zuberoako testuen corpusean ahalerazko balioa 38 aldiz ageri da, eta desirazkoa behin baizik. Bestenaz, preseski adierazi behar dugu Zuberoako testuetan ez dela ahalko edo ezinen bakar bat ere, EKCren emaitzekiko koherentzian: ahalko Lapurdin eta Nafarroa Beherean lekukotzen da, baina ez Zuberoan. Beraz, ahallezin parearekiko perifrasi berrietan -i.e., izan \& "edun laguntzaileekikoetan- geroaldia partizipio prospektiboaren bidez adierazia da. Horrek, hein batean, ekialdean ahal partikularen gramatikalizazioa beste eremuetan baino gibelatuago dela iradoki lezake. 


\subsection{Jainkoari lotutako formulak}

'Nahi' edo 'maite ukan' erran-nahia duten erro zaharrak ohikoak dira Jainkoaren pean adierazten diren igurikimen eta desioetan. Optatibo gramatikalean ageri den Jainkoak ailiotsa (15 \& 30-33) erranbidearen baliokidea da Jainkoak baletsa, optatibotik baldintzara iraganik ${ }^{32}$. Zuberoan, aditzaren erregimen zaharra -datiboa, iragangaitz- testurik zaharrenetan ageri da (120). Geroztik, gehienbat Maisterrek du formula hori baliatu (121-129); azken etsenpluak trajeria zahar batean (130) eta 1856ko pietate liburu batean atzeman ditugu (131).

(120) Baletsa jaungoikoari / Har nezan zerbitzari / Hark er', eta leristan / hanbat on zein nik hari. «S'il plaisait à Dieu qu'elle me prît pour serviteur et qu'elle m'aimât autant que je l'aime» (O Po XIII 25)

(121) Nitçaç dena beçambat, ఏيncouac balexa, enian ulkhen beste dessegnic batere. (Mst XVI)

(122) \incouac balexa hen bicitcia, jakitiaren araur içan liçan! (Mst I 3, 6)

(123) \incouac balexa, deboten hanitch exemplu ikhous oundouan, goure berthutian aitcinatceco desira lo elagouen ardura. (Mst I 18, 6)

(124) ఏincouac balexa, egun bakhoitç bateç, ounxa bici içan guinen mundu hountan! (Mst I 23, 2)

(125) Jincouac balexa, halaco beharric eliçan, eta arimac behar lutian errekeitiac gogouan ukhen guintçan! (Mst I 25, 9)

(126) Behar citit segurki soferitu, İncouac balexa, pacentciareki liçan, iraçarri haur igaren, eta thempora hobebat jin artio. (M.st III 29, 2)

(127) Jincouac balexa, enendin esteca guero jin behar dien gaicer, eta çoure boronthate hounari, berankeriaric gabe, oberenda neçan ene buria. (Mst III 39, 1)

(128) O \incouac balexa, egun houra jin liçan, eta mundu hountaco gaiça themporalac oro acabi liren! (Mst III 48, 1)

(129) Jincouac balexa aldi bakhoitç bateç ere oren erdiaren araoua behar den beçala emplegatcen jakin nian! (Mst IV 1, 4)

(130) Har eçaçu behar den armada / eman behar baduçu ere guerla / Celuco gincouac balexa / ukheitez Çuc Victoria (Jean de Paris 85)

(131) \incöac baletsa bihar liçatekian egun houra. (MaiMarHil 95)

Lafittek zerbait iruzkin egin zuen erramolde honetaz: «La vieille formule Jainkoak baletsa... plaise à Dieu, nous paraît plus locale, mais elle n'existe presque plus. [...] On rencontre une formule analogue dans les écrits de Hiriart-Urruty: Jainkoak ailema Que Dieu accorde...» (2008 [1944]: § 722). Beste formula hori, (Jinkoak) ailemo edo ailema, ez da Zuberoako testuetan ageri. Bestenaz, erro bera aurki daiteke jusibo gisara jokatua, datiboan nahiz ergatiboan (132-140); egitura horrek eta Jainkoak baletsa formulak ber kronologia dute.

32 Ez dakigu forma hauek zehazki zein errori dagozkion. Lafitterendako baletsa «suppositif de etsi, juger bon (si au moins Dieu jugeait bon)» litzateke (2003 [1948]: 745). 
(132) Iencoari datsala, eguitecoa erditi Ioan dadin. (Tt Onsa 78)

(133) Iencoari datsala pensamendu saindu hura cian beré gogoan. (Tt Onsa 124)

(134) Ene khostuç hori ikhassi dit, eta \incouac dexala, eni gogoua haboro har eracitceco den, eta eç erhokeriala eiçteco. (Mst III 45, 4)

(135) Incouac daxala gracia hori merechi deçadan. (Mst III 56, 5)

(136) Oroc behar diçugu hil / çoure espousa maitiac beçala, / houra beçain justoky / Gincouac dexala. (StJul 466)

(137) Parropia hortaco fidelac gin balite indigne içatera confrariaco dohaignen -Gincoac eztatsala- bere condutaz. (Mercy 18)

(138) Eta \inkuak detsala Erregetiar traidore hoiek profeita eztitian, berek erakharri dien estatu miserable hunez. (Chaho AztiB V)

(139) Egün hun, künpaña ederra, / bai eta ilüstria; / \inkuoak detsala harzara berriz / alkhar salüta erriz. (CanBel 101)

(140) \incöac detsala liburu hau iracourriren dienec bere salbamentiaren eguin beharrez antsiatsiago içan ditian. (MaiMarHil 7-8)

\section{ONDORIOAK}

Euskara historikoan, igurikimen eta desioen adierazpena zenbait baliabide morfosintaktikoren medioz gauzatu izan da; horietan bereziena da ai(t)- aurrizkiaren bidez jokatzen den modu optatiboa. $A i(t)$ - aurrizkidun formak aski bakanak izan arren, ongi eta segurki lekukotuak dira euskararen geografia osoan: mendebalde, erdialde zein ekialdeko testuetan ageri dira. Beraz, optatiboa dudarik gabe euskararen behialako ezaugarri orokorra izan zen, hots, zatiketa dialektala baino lehenagokoa.

Optatiboak Zuberoan iraun du inon baino luzeago, testigantzen arabera xIx. edo Xx. mendera arte, ekialdeko ekialdean -Biarnoko Eskiulan eta Jeruntzen- gordea omen delarik. Ideia horrekiko kontraste bizian, ai $(t)$-dun optatiboak arras gutxitan ageri dira Zuberoa eta aldirietako testuetan: XviII. mendera arte orotara lauzpabost agerraldi bildu dugu. Hizkuntza osoari pentsa, ondoriozta daiteke xviıI. mendean optatiboa aski galdua zatekeela euskal herri gehienetan: idazle ikasiak alde batera utzirik, kasik adibide guztiak Euskara Arkaiko eta Zaharrekoak dira. xıx. mendean Inchauspek agerraldi andana bat ematen du, oroz gainetik bere Imitacionian, gure ustez hautu batengatik. Azkenik, xx. mendeko zenbait idazlek ai(t)- aurrizkiarekiko jokoa berpiztuko dute, halako estilema bihurtuz.

Lekukotasunek erakusten dutenez, euskararen modu optatiboa ezaugarriztatzen duen morfema ait- da garbiki, eta ez ai-. Mendebaldeko ei(t)- alomorfoa ei partikula modalarekin lotua izan bada ere, guretzat ez da batere seguru ai(t)- eta ei sorburu berekoak izan daitezen. $A i(t)$ - aurrizkiaren jatorriaz denaz bezainbatean, bi aukera kontsideratu dugu: i) ai auhenezko interjekzioa, aikünu \& aitzina bezalako aldaketa fonetikoak bait- \& albait- aurrizkidun formekiko analogiaz azaldurik; edo ii) *bait- zahar bat, beharbada baldintzazko balioaz hornitua. Kronologikoki, ai(t)- aurrizki bizi bakanetakoa eta mintzo guztietakoa izateak Euskara Batu Zaharrera igortzen du. 
Esperantzaren eta desioaren gainerako adierazpideei doakienean, aldi historikoan baldintzazko egiturak hedatuz doaz. Horietan sinpleena da $b a$ - aurrizkiarekiko adizkia baliatzea, zenbaitetan ai interjekzioaz lagundurik. Testu zaharrenetan alba- aurrizki konplexuak ere balio bera adieraz dezake. Jada Axularrengan lekukotua, balinba (balima) partikula ekialdean hedatzen da XVIII. mendean, bereziki herri tradizioko testuetan. Paraleloki, Penintsulako erromantzeei mailegatu oxala partikula XVIII. mendean azaleratzen da, Lapurdira ere hedatuz -baina ez, xIx. mendera arte bederen, ekialderago-. Bestenaz, XVIII. mendetik aitzina, Zuberoan aments ba-moldea lekukotzen da. Mendebaldean, XVII. mendean ahal partikula desirazko balioaz hasten da lekukotzen, partizipio prospektiboarekiko egituran, eta XIX. menderako iparraldera ere hedatzen da -Akitaniako mintzoetan egitura horretatik kanpo ere ezagun da, galderazko perpausetan-. Azkenik, hizkuntza gehienek bezala, euskarak ere Jainkoari lotutako formulak garatu ditu: Jinkoak datsala/ baletsal ailiotsa/ ailemo.

Gure ustez, ai(t)- moldeko optatiboak Zuberoako testuetan egiazki izan duen agerpen arras marjinalak ez du justifikatzen xx. mendean sortu den irudia, zeinaren arabera adizkera hori zubereraren ezaugarri gisara aipatzen ohi baita, zenbaitetan bereizgarri ere. Aldiz, euskal optatiboa tipologikoki elementu bakana, eta diakronikoki komun eta zaharra izateagatik, ordu zuen, hizkuntzaren ezaugarrien artean, bere garrantzia aitor geniezaion. 


\section{ERREFERENTZIAK}

Bilbao, G. et al., (prestatzen), «Etxart-Ros gutuneria» bilduma, Vitoria-Gasteiz, UPV/ EHU. Sarean: <http://www.ehu.eus/monumenta/tz/?b=1> (azken kontsulta: 2016-11-08).

Bonaparte, L. L., 1869, Le verbe basque en tableaux, accompagné de notes grammaticales, selon les huit dialectes de l'euskara..., Londres, Strangeways \& Walden [berrarg. in Opera Omnia Vasconica I, 175-442].

Bybee, J. L.; Fleischman, S., 1995, Modality in Grammar and Discourse, Amsterdam/ Philadelphia , John Benjamins.

Bybee, J. L.; Perkins, R.; Pagliuca, W., 1994, The evolution of grammar. Tense, Aspect and Modality in the Languages of the World, Chicago/ New York, The University of Chicago Press.

CAmino, I., 2011, «Ekialdeko euskararen iraganaz», in I. Epelde (arg.), Euskal dialektologia: lehena eta oraina, Bilbao, UPV/EHU, «ASJUren Gehigarriak», 69, 87-153 or.

- 2013, Alphonsa Rodriguez Jesusen Compagnhaco Aitaren guiristinho perfeccioniaren Praticaren pparte bat (1782). Edizioa eta azterketa, Bilbao, Euskaltzaindia \& UPV/EHU.

Casenave-Harigile, J., 1993, Hiztegia II. Eüskara - Frantses. Xiberotar eüskalkitik abiatzez, Ozaze-Zühara, Hitzak.

Снано, А.; D’Aвваdie, A., 1836, Études grammaticales sur la langue euskarienne, Paris, A. Bertrand.

Dobrushina, N.; Van Der Auwera, J.; Goussev, V., 2013, «The Optative», in M. Dryer; M. Haspelmath (arg.), The World Atlas of Language Structures Online, Leipzig, Max Planck Institute for Evolutionary Anthropology. Sarean: <http://wals.info/chapter/73> (azken kontsulta: 2016-11-17).

Etxagibel, J., 2014, «Pouvreauren hiztegia testukritika eta metalexikografiaren argitan», Vitoria-Gasteiz, UPV/EHU, doktorego tesia.

Etxebarne, J., 2011, Gramatika emendakinak. Zuberoako euskaraz, Bilbao, Euskaltzaindia.

ETXegorri, P., 2003, «Jeruntzeko Üskara. Ekialdeko euskara», FLV, 93, 247-285 or.

— 2007, «Mugako zuberotarrak», in Mendebaldeak badu ekialdea: Zuberoa, hizkuntza, literatura eta etorkizuna (XI. Jardunaldiak), Bilbao, Mendebalde Kultura Alkartea, 53-76 or.

EuSKALTZAINDiA, 1987, Euskal gramatika. Lehen urratsak - II, Bilbao.

- 2002, Euskal gramatika laburra: perpaus bakuna, Bilbao.

Gavel, H.; Lacombe, G., 1937, Grammaire basque. Tome II. Le verbe, Baiona, Imprimerie de la Presse.

GÈzE, L., 1873, Éléments de grammaire basque. Dialecte souletin, Baiona, Lamaignère.

Haritschelhar, J., 1969 -1970, «L'oeuvre poétique de Pierre Topet-Etchahun», Euskera, 14-15.

Haspelmath, M., 2010, "Comparative concepts and descriptive categories in crosslinguistic studies», Language, 86 (3), 663-687 or.

Hovelacque, A.; Рicot, É.; Vinson, J., 1880, Mélanges de linguistique et d'anthropologie, Paris, Leroux. 
Hualde, J. I.; Ortiz de Urbina, J. (arg.), 2003, A Grammar of Basque, Berlin/ New York, Mouton de Gruyter.

Inchauspe, E., 1858, Le verbe Basque, Baiona, Lamagnière.

Ithurry, J., 1895, Grammaire basque. Dialecte labourdin, Baiona, Lamagnière.

Jaureguiberry, C., 1957, "Le verbe basque souletin. Analyse du mécanisme de sa conjugaison", Eusko Jakintza, 1957, 69-87 or.

Jendraschek, G., 2003, «L'évolution diachronique de l'expression de la possibilité en basque ", Lapurdum, 8, 263-283 or.

KrajewsKa, D., 2017, «Euskararen sintaxi diakronikorantz: menpeko perpausak» Vitoria-Gasteiz, UPV/EHU, doktorego tesia, prestatzen.

LAFitTe, P., 1980, «Aspektua euskal aditzean», Euskera, 25 (2), 483-498 or.

- 2003 [1948], "La proposition exclamative en navarro-labourdin», VIIème Congrès d'Études Basques [arg. 7. 1948. Biarritz, Eusko Ikaskuntza, Donostia], 743-746 or.

- 2008 [1944], Grammaire basque. Navarro-labourdin littéraire, Donostia, Elkar.

LAFON, R., 1944, Le système du verbe basque au Xvie siècle, Bordele, Éditions Delmas [berrarg. 1980, Donostia, Elkar].

- 1966, «La particule bait en basque : ses emplois morphologiques et syntactiques», Bulletin de la Société Linguistique de Paris, 61 (1), 217-248 or.

LAKARRA, J. A., 1986, «Bizkaiera zaharra euskalkien artean», ASJU, 20 (3), 639-82 or. Larrasquet, J., 1939, Le basque de la Basse Soule Orientale, Paris, Klincksieck.

Lhande, P., 1926, Dictionnaire basque-français, Paris, Beauchesne.

Michelena, L., 1964, Textos arcaicos vascos, Madril, Minotauro [berrarg. in «ASJUren Gehigarriak», 11].

Mounole, C., 2003, C. H. de Belsunce bizkondea. Tableau analytique et grammatical de la langue basque (1858). Azterketa eta edizioa, ASJU, 37 (2).

— 2011, «Le verbe basque ancien: étude philologique et diachronique» UPV/EHU \& Université Michel de Montaigne - Bordeaux 3, doktorego tesia.

Musi, E., 2016, «Towards a unified account of linguistic typology and anthropology: the expression of desire in the world's languages», eskuizkribua, Lugano, Università della Svizzera italiana (USI).

Oinenart, A., 1656, Notitia Vtriusque Vasconiae, Paris, Cramoisy.

Oyharçabal, B., 1987, Étude descriptive de constructions complexes en basque: Propositions relatives, temporelles, conditionnelles et concessives, Paris, CNRS, Estatuko doktorego tesia.

— 1997, «Hiru aditz aurrizki zahar 16. mendeko testuetan», Lapurdum, 2, 45-62 or. Rice, K., 1989, A Grammar of Slave, Berlin/ New York, Mouton de Gruyter.

SAdock, J. M.; Zwicky, A. M., 1985, "Speech Acts Distinctions in Syntax», in T. Shopen (arg.), Language Typology and Syntactic Description. Vol. I: Clause structure, Cambridge, Cambridge University Press, 155-196 or.

Saltarelli, M. et al., 1988, Basque (Croom Helm Descriptive Grammars), Londres, Croom Helm.

Sarasola, I., 1983, Contribución al estudio y edición de textos antiguos vascos, Donostia, Gipuzkoako Foru Aldundia \& UPV/EHU, «ASJUren Gehigarriak», 11. 
Trask, R. L., 1993, A dictionary of grammatical terms in linguistics, Londres/ New York, Routledge.

Urgell, B., 2000, «Larramendiren Hiztegi hirukoitza-ren osagaiez», Vitoria-Gasteiz, UPV/EHU, doktorego tesia.

- 2015, Gero (edizio kritikoa), Iruñea, Nafarroako Gobernua \& Euskaltzaindia, «Mendaur», 6.

Urkizu, P., 1998, Zuberoako irri teatroa. Recueil des farces charivariques basques, Baigorri, Izpegi.

Urquijo, J., 1910, «Notes d'Oihenart pour le vocabulaire de Pouvreau», RIEV, 4 (2), 220-232 or.

VAn Eys, W. J., 1879, Grammaire comparée des dialectes basques, Paris, Maisonneuve. ZuAZo, K., 1989, «Zubereraren sailkapenerako», ASJU, 23 (2), 609-50 or.

Zubiri, I.; Zubiri, E., 2000, Euskal Gramatika Osoa, Bilbao, Didaktiker.

\section{LABURPENA}

\section{Zozo zuriaren xerka: euskararen optatiboaren historia}

Munduko hizkuntza guztiek igurikimen eta desioak adieraz ditzaketen arren, soilik gutxiengo batek du funtzio horretarako flexio berezia aditzean, modu optatibo deitua. Orain arte, zubereraren deskripzio guztiek optatiboaren existentzia nabarmendu dute, ai $(t)$ - aurrizkidun formen paradigmarekin. Euskara historikoan, hala mendebaldean nola erdialdean ere, halako formak lekukotuak dira, optatiboa behiala hizkuntza osoaren ezaugarria zelako frogantza. Lan honetan euskararen optatiboaren deskripzio diakroniko bat eskaini nahi dugu. Optatibozko formen lekukotza, eremua eta iraupena azterturik, ai $(t)$ - aurrizkiaren jatorriaren gaineko hipotesi bat formulatuko dugu. Azkenean, igurikimen eta desioen gainerako adierazpideak aztertuko dira.

Gako hitzak: aditz morfologia; modalitatea; optatiboa; zuberera.

\section{RESUMEN}

\section{Buscando un mirlo blanco: la historia del optativo vasco}

Pese a que todas las lenguas del mundo son capaces de expresar el deseo y la esperanza, sólo algunas de ellas disponen de una estrategia flexiva a tal fin: el modo optativo. Todas las descripciones del dialecto suletino han incidido en la existencia del modo optativo, materializado en formas verbales portando el prefijo ai $(t)$-. En vasco histórico, tales formas han sido documentadas además en los dialectos occidentales y centrales, prueba de que en una época anterior el optativo fue un rasgo común de la lengua. Este 
trabajo pretende ofrecer una visión diacrónica del optativo vasco. Tras examinar la atestiguación de formas de optativo, su extensión y duración, formularemos una hipótesis sobre el origen del prefijo ai $(t)$-. Finalmente, examinaremos brevemente otras vías de expresión del deseo y la esperanza en vasco.

Palabras clave: morfología verbal; modalidad; optativo; dialecto suletino.

\section{ABSTRACT}

\section{Searching for a rara avis: the history of Basque optative}

Though all languages are able to convey hopes and desires, only some among them have a specific verbal inflection for this purpose, the optative mood. Up to now, every grammatical description of Souletin Basque (Eastern dialect) has emphasized the existence of the optative mood, with verbal forms showing the prefix ai $(t)$-. In historical Basque, such forms are attested also in western and central dialects; thus, the optative mood undoubtedly was a common feature of Basque. The aim of this paper is to offer a diachronic description of Basque optative. We will address the optative forms, their extension in space and time, and we shall propose a hypothesis on the origin of the prefix $a i(t)$-. Finally, we will succinctly describe other ways of expression of hopes and desires in Basque.

Keywords: verbal morphology; modality; optative; Souletin dialect. 